\title{
Phosphoproteomic Landscape of AML Cells Treated with the ATP-Competitive CK2 Inhibitor CX-4945
}

\author{
Mauro Rosales ${ }^{1,2,+}{ }^{\mathbb{D}}$, Arielis Rodríguez-Ulloa ${ }^{3,+}$, Vladimir Besada ${ }^{3}$, Ailyn C. Ramón ${ }^{2}$, George V. Pérez ${ }^{2}$, \\ Yassel Ramos ${ }^{3}$, Osmany Guirola ${ }^{4}{ }^{(0}$, Luis J. González ${ }^{3}$, Katharina Zettl ${ }^{5}$, Jacek R. Wiśniewski ${ }^{5}$, Yasser Perera ${ }^{2,6, *}$ \\ and Silvio E. Perea ${ }^{2, *(1)}$
}

check for

updates

Citation: Rosales, M.;

Rodríguez-Ulloa, A.; Besada, V.;

Ramón, A.C.; Pérez, G.V.; Ramos, Y.;

Guirola, O.; González, L.J.; Zettl, K.;

Wiśniewski, J.R.; et al.

Phosphoproteomic Landscape of AML Cells Treated with the ATP-Competitive CK2 Inhibitor CX-4945. Cells 2021, 10, 338.

https://doi.org/10.3390/

cells10020338

Academic Editor: Zhixiang Wang

Received: 26 October 2020

Accepted: 2 February 2021

Published: 5 February 2021

Publisher's Note: MDPI stays neutral with regard to jurisdictional claims in published maps and institutional affiliations.

Copyright: (c) 2021 by the authors. Licensee MDPI, Basel, Switzerland. This article is an open access article distributed under the terms and conditions of the Creative Commons Attribution (CC BY) license (https:/ / creativecommons.org/licenses/by/ $4.0 /)$.
1 Department of Animal and Human Biology, Faculty of Biology, University of Havana (UH), Havana 10400, Cuba; mauro.rosales@fbio.uh.cu

2 Molecular Oncology Group, Department of Pharmaceuticals, Biomedical Research Division, Center for Genetic Engineering and Biotechnology (CIGB), Havana 10600, Cuba; ailyn.ramon@cigb.edu.cu (A.C.R.); george.perez@cigb.edu.cu (G.V.P.)

3 Mass Spectrometry Laboratory, Proteomics Group, Department of Systems Biology, Biomedical Research Division, CIGB, Havana 10600, Cuba; arielis.rodriguez@cigb.edu.cu (A.R.-U.); vladimir.besada@cigb.edu.cu (V.B.); yassel.ramos@cigb.edu.cu (Y.R.); luis.javier@cigb.edu.cu (L.J.G.)

4 Bioinformatics Group, Department of Systems Biology, Biomedical Research Division, CIGB, Havana 10600, Cuba; osmany.guirola@cigb.edu.cu

5 Biochemical Proteomics Group, Department of Proteomics and Signal Transduction, Max-Planck Institute of Biochemistry, 82152 Munich, Germany; zettl@biochem.mpg.de (K.Z.); jwisniew@biochem.mpg.de (J.R.W.)

6 China-Cuba Biotechnology Joint Innovation Center (CCBJIC), Yongzhou Zhong Gu Biotechnology Co., Ltd, Lengshuitan District, Yongzhou 425000, China

* Correspondence: ypereranegrin@ccbjic.com (Y.P.); silvio.perea@cigb.edu.cu (S.E.P.)

+ These authors contributed equally to this work.

Abstract: Casein kinase 2 (CK2) regulates a plethora of proteins with pivotal roles in solid and hematological neoplasia. Particularly, in acute myeloid leukemia (AML) CK2 has been pointed as an attractive therapeutic target and prognostic marker. Here, we explored the impact of CK2 inhibition over the phosphoproteome of two cell lines representing major AML subtypes. Quantitative phosphoproteomic analysis was conducted to evaluate changes in phosphorylation levels after incubation with the ATP-competitive CK2 inhibitor CX-4945. Functional enrichment, network analysis, and database mining were performed to identify biological processes, signaling pathways, and CK2 substrates that are responsive to CX-4945. A total of 273 and 1310 phosphopeptides were found differentially modulated in HL-60 and OCI-AML3 cells, respectively. Despite regulated phosphopeptides belong to proteins involved in multiple biological processes and signaling pathways, most of these perturbations can be explain by direct CK2 inhibition rather than off-target effects. Furthermore, CK2 substrates regulated by CX-4945 are mainly related to mRNA processing, translation, DNA repair, and cell cycle. Overall, we evidenced that CK2 inhibitor CX-4945 impinge on mediators of signaling pathways and biological processes essential for primary AML cells survival and chemosensitivity, reinforcing the rationale behind the pharmacologic blockade of protein kinase CK2 for AML targeted therapy.

Keywords: phosphoproteomics; casein kinase 2; kinase inhibitor; CX-4945; acute myeloid leukemia

\section{Introduction}

Protein phosphorylation is an essential post-translational modification in most cellular processes, making of protein kinases promising therapeutic targets for a wide variety of disorders, including cancer [1,2]. Among the protein kinases involved in cell signaling networks, casein kinase 2 (CK2) is responsible of about $25 \%$ of all cell phosphoproteome [3]. CK2 is a constitutively active and ubiquitously expressed Ser/Thr-protein kinase composed of two catalytic subunits ( $\alpha$ or its isoform $\alpha^{\prime}$ ) and two regulatory subunits ( $\beta$ ) [4]. The 
CK2 consensus sequence (pS/pT-x1-x2-E/D/pS/pT, in which $\mathrm{x} 1 \neq \mathrm{P})$, is a small motif characterized by several acidic residues in the proximity of the phosphorylatable amino acid, as well as the absence of basic residues in those positions [5]. Concerning CK2 substrates, about one third are involved in gene expression and protein synthesis, while numerous are signaling proteins implicated in cell growth, proliferation, and survival $[3,6]$. Moreover, a small number of CK2 substrates are classical metabolic enzymes or associated with some virus life cycle [3].

Protein kinase CK2 has been linked to basically all the hallmarks of malignant diseases $[7,8]$. Accordingly, several CK2 inhibitors have been described, including small organic compounds designed to target the ATP-binding site on the CK2 catalytic subunit, flavonoids and a synthetic cell-permeable peptide termed CIGB-300, originally designed to block CK2-mediated phosphorylation through binding to phosphoacceptor domain in the substrates [9-11]. Additionally, a cyclic peptide that antagonizes the interaction between the CK2 $\alpha$ and $\beta$ subunits and antisense oligonucleotides that reduce CK2 alpha subunit transcription have also been explored $[12,13]$. However, only the ATP-competitive inhibitor CX-4945 and the synthetic peptide CIGB-300 have advanced to human clinical trials in and shall provide proof-of-concept for CK2 as a suitable oncology target [14,15].

Acute myeloid leukemia (AML) is one of the most frequent hematologic malignancies and high-expression of $\mathrm{CK} 2 \alpha$ subunit has been connected to a worse prognosis in AML patients with normal karyotype [16,17]. Actually, CK2 is implicated in multiple signaling pathways, all of them essential for hematopoietic cell survival and function, and leukemic cells have been demonstrated to be more sensitive to downregulation of protein kinase CK2 $[18,19]$. The latter becomes particularly relevant since AML stand among the most aggressive and lethal types of cancer and are often characterized by resistance to standard chemotherapy as well as poor long-term outcomes [20].

In recent years, quantitative phosphoproteomic approaches have been useful to explore the cellular response to kinase inhibition in different types of cancer cells [21]. In fact, the proteomic and phosphoproteomic patterns associated with prognosis of AML patients and its progression from diagnosis to chemoresistant relapse has been recently described, studies that suggested the importance of CK2 for chemosensitivity in human AML primary cells $[22,23]$. Besides, the CK2-dependant phosphoproteome has been explored by quantitative phosphoproteomic using not only CK2 inhibitors in HEK-293T, HeLa, and NCI-H125 cells, but also through genetic manipulation of CK2 subunits in C2C12 cells [24-27]. However, the impact of CK2 inhibition has not been widely assessed in AML cells, since to our knowledge no previous phosphoproteomic studies have been conducted for CK2 inhibitors in this particular hematological pathology. Considering the above, we decided to explore the CK2-regulated phosphoproteome and the consequent signaling networks perturbations induced after exposure of AML cells to CK2 inhibitor CX-4945. Mass spectrometry (MS)-based phosphoproteomics profiling allowed us to gauge the global impact of CX-4945 in human cell lines representing two differentiation stages and major AML subtypes.

\section{Materials and Methods}

\subsection{Cell Culture}

Human AML cell lines HL-60 and OCI-AML3 were originally obtained from the American Type Culture Collection (ATCC, Manassas, VA, USA) and the German Collection of Microorganisms and Cell Cultures (DSMZ, Braunschweig, Germany), respectively. Both cell lines were cultured in RPMI 1640 medium (Invitrogen, Carlsbad, CA, USA) supplemented with 10\% $(v / v)$ fetal bovine serum (FBS, Invitrogen, Carlsbad, CA, USA) and $50 \mu \mathrm{g} / \mathrm{mL}$ gentamicin (Sigma, St. Louis, MO, USA). Cells were maintained under standard cell culture conditions. 


\subsection{Sample Preparation and Phosphopeptide Enrichment}

HL-60 and OCI-AML3 cells ( $10^{7}$ cells per each condition, three biological replicates) were treated or not with $5 \mu \mathrm{M}$ CX-4945 (Selleck Chemicals, Houston, TX, USA) for $8 \mathrm{~h}$. After collected by centrifugation and washed with PBS, cells were resuspended in lysis buffer containing $2 \%$ SDS and $50 \mathrm{mM}$ DTT. Samples were boiled at $95{ }^{\circ} \mathrm{C}$ for $10 \mathrm{~min}$ and proteins were extracted by multienzyme digestion filter-aided sample preparation (MED-FASP) with overnight lys-C and tryptic digestions [28]. Phosphopeptides were then enriched from each digestions using $\mathrm{TiO}_{2}$ beads as previously described [29]. For enrichment, "Titansphere $\mathrm{TiO}_{2} 10 \mu \mathrm{m}$ " (GL Sciences, Inc., Tokyo, Japan) was suspended in $200 \mu \mathrm{L}$ of $3 \%(\mathrm{~m} / \mathrm{v})$ dihydroxybenzoic acid in $80 \%(v / v) \mathrm{CH}_{3} \mathrm{CN}, 0.1 \% \mathrm{CF}_{3} \mathrm{COOH}$ and diluted 1:4 with water and later used at a 4:1 ratio (mg beads: $\mathrm{mg}$ peptides). $\mathrm{Next}, 2 \mathrm{mg} \mathrm{\textrm {TiO } _ { 2 }}$ (per mg peptides) was added to each sample and incubated at room temperature under continuous agitation for $20 \mathrm{~min}$. The titanium beads were sedimented by centrifugation and the supernatants were collected and mixed with another portion of the beads and incubated as above. The bead-pellets were resuspended in $150 \mu \mathrm{L}$ of $30 \%(v / v) \mathrm{CH}_{3} \mathrm{CN}$ containing $3 \%(v / v) \mathrm{CF}_{3} \mathrm{COOH}$ and transferred to a $200 \mu \mathrm{L}$ pipet tip plugged with one layer of Whatman glass microfiber filter GFA (Sigma, St. Louis, MO, USA). The beads were washed 3 times with $30 \%(v / v) \mathrm{CH}_{3} \mathrm{CN}, 3 \% \mathrm{CF}_{3} \mathrm{COOH}(v / v)$ solution and 3 times with $80 \% \mathrm{CH}_{3} \mathrm{CN}(v / v), 0.3 \% \mathrm{CF}_{3} \mathrm{COOH}(v / v)$ solution. Finally, the peptides were eluted from the beads with $100 \mu \mathrm{L}$ of $40 \% \mathrm{CH}_{3} \mathrm{CN}(v / v)$ containing $15 \% \mathrm{NH}_{4} \mathrm{OH}(\mathrm{m} / v)$ and were vacuum-concentrated to $\sim 4 \mu \mathrm{L}$. Phosphopeptides were further desalted by Stage procedure [30].

\subsection{NanoLC-MS/MS and Data Analysis}

Chromatographic runs for phosphopeptides and non-phosphopeptides were in homemade column (75 mm ID, $20 \mathrm{~cm}$ length). For phosphopeptides, was used a gradient from $5 \%$ buffer B $(0.1 \%$ formic acid in acetonitrile) up to $30 \%$ in $45 \mathrm{~min}$, then increase to $60 \%$ in $5 \mathrm{~min}$, and up to $95 \%$ in $5 \mathrm{~min}$ more. Meanwhile for non-phosphopeptides the gradient started at $5 \%$ buffer B up to $30 \%$ in $95 \mathrm{~min}$, then increase to $60 \%$ in $5 \mathrm{~min}$, and up to $95 \%$ in 5 min more. An EASY-nLC 1200 system coupled to a QExactive HF mass spectrometer (both from Thermo Fisher Scientific, Waltham, MA, USA) was used with the nanocolumn being at $60^{\circ} \mathrm{C}$. Peptides were detected in the mass range $300-1650 \mathrm{~m} / \mathrm{z}$ using data-dependent acquisition and each mass spectrum was obtained at 60,000 resolution (20 ms injection time) and followed by $15 \mathrm{MS} / \mathrm{MS}$ spectra (28 ms injection time) at 15,000 resolution. Identification of peptides and proteins was based on the match-between-runs procedure using MaxQuant software (v1.6.2.10) [31], and considering oxidation (M), deamidation (NQ), $\mathrm{N}$-terminal acetylation (proteins) and phosphorylation (STY) as variable modifications. None fixed modifications were considered as cysteines were not modified. Alignment of chromatographic runs were allowed with default parameters $(20 \mathrm{~min}$ time window and a matching of 0.7 mins between runs). Filtering and quantification of phosphopeptides were performed in Perseus computational platform (v1.6.2.2) [32]. Reverse and potential contaminant hits were removed, while only phosphosites with localization probability above 0.75 were retained for further analysis. Student's $t$ Test was employed to identify statistically significant changes ( $p$-values lower than 0.05 ) in phosphorylation and protein levels, after filtering for two valid values in at least one group. An additional fold-change (treated vs. control) cutoff of 1.5 was also applied.

\subsection{Enrichment Analysis and Sequence Logo}

Biological processes significantly represented in differentially-phosphorylated proteins were identified through functional annotation and enrichment analysis, based on the information annotated in the Gene Ontology (GO) database (http:/ / www.geneontology. org/ (accessed on 2 February 2021)) [33,34]. Analysis was performed with DAVID (v6.8) web-based tool (http:/ / david.ncifcrf.gov/ (accessed on 2 February 2021)) and all identified phosphoproteins dataset was used as background [35,36]. DAVD computes EASE-score, a 
modified Fisher Exact Test to identify significant enriched biological processes ( $p$-values lower than 0.1 ) $[35,36]$. The resulting list of GO terms with its corresponding $p$-values was further submitted to REViGO (http:/ / revigo.irb.hr/ (accessed on 2 February 2021)) for redundancy reduction [37]. In addition, sequence logos for down-regulated phosphopeptides were generated using WebLogo (v3.6.0) (http:/ / weblogo.threeplusone.com/ (accessed on 2 February 2021)) and MaxQuant amino acid sequence window was used as input [38].

\subsection{Enzyme-Substrate Relationship and Kinome Network Analysis}

Enzyme-substrate-site relations were retrieved using the integrated protein posttranslational modification network resource iPTMnet [39]. iPTMnet is based on a set of curated databases like PhosphoSitePlus (http:/ / www.phosphosite.org (accessed on 2 February 2021)) and PhosphoEML (http:/ / phospho.elm.eu.org (accessed on 2 February 2021)), which annotate experimentally observed post-translational modification $[40,41]$. Besides, the KEA2 web tool (https: / / www.maayanlab.net/KEA2/ (accessed on 2 February 2021)) was used, first to retrieve information about kinases responsible for phosphoproteome modulation after CK2 inhibition, and second to identify which of such kinases were enriched based on the phosphoproteomic profile [42]. KEA2 is based on an integrative database of kinase-substrate interactions derived from disparate source including literature [42]. The software computes a Fisher Exact Test to distinguish significant enriched kinases ( $p$-values lower than 0.05), through statistical analysis [42]. To represent the kinome network, the interactions among the protein kinases associated to the phosphoproteomic profile, according to KEA2 and iPTMnet annotations, were retrieved using the Metascape gene annotation and analysis resource (http: / / metscape.org (accessed on 2 February 2021)) [43]. Such bioinformatics software compiles the information from different integrative databases and applies the MCODE algorithm to extract highly connected regions or complexes embedded in proteins networks [44].

\subsection{Identification and Analysis of CK2 Substrates}

In addition to bona fide CK2 substrates, we searched for candidate substrates based on: (1) the presence of the CK2 consensus sequence (pS/pT-x1-x2-E/D/pS/pT, x1 $\neq \mathrm{P}$ ) [5], (2) the enzyme-substrate predictions retrieved from NetworKIN database [45], (3) the dataset of high confidence CK2 substrates reported by Bian et al. [46] and (4) the phosphoproteins which interact with CK2 according to Metascape database information [43]. Substrates that met at least two of such criteria were selected as the most reliable for further functional analysis. All identified substrates (bona fide and putative) were represented in a network context and classified according to biological processes annotated in GO database [33,34], and the STRING database (http: / / string-db.org/ (accessed on 2 February 2021)) was used to identify interactions between proteins [47]. In such analysis only databases and experimental evidences were used as source of interaction data and the confidence score was fixed at 0.4 . All protein-protein interaction networks (kinome network and CK2 substrates network) were visualized using Cytoscape software (v.3.5.0) [48].

\section{Results and Discussion}

\subsection{Profiling the CX-4945-Responsive Phosphoproteome in AML Cells}

Advances in high throughput technologies and bioinformatic tools for subsequent data analysis, make possible to explore on a wide-scale fashion the cellular response to inhibition of protein kinases. Particularly, phosphoproteomic studies provide solid evidences regarding kinase-substrates and kinases-kinases relationships involved in the complexity of networks regulating cellular processes in health and disease. Hence, we decided to explore the CK2-regulated phosphoproteome in AML cells using MS-based phosphoproteomic analysis of HL-60 and OCI-AML3 cells treated or not with $5 \mu \mathrm{M}$ of the CK2 inhibitor CX-4945 during $8 \mathrm{~h}$ (Figure 1A). Of note, the inhibitory effect of CX4945 over CK2 enzymatic activity has been previously evidenced by reduction of bona fide CK2 substrates phosphorylation and immunoblotting with antibody against pan- 
CK2 phosphorylated motif [25,49]. In addition, as measured using AlamarBlue assay, CX-4945 showed a similar dose-dependent inhibitory effect on HL-60 and OCI-AML3 cells proliferation, with $\mathrm{IC}_{50}$ values of $7.49 \pm 1.55 \mu \mathrm{M}$ and $4.69 \pm 1.59 \mu \mathrm{M}$, respectively (Figure S1A). AML is a highly heterogenous disease, and selected cell lines derive from the most common AMLs (i.e., acute promyelocytic and acute myelomonocytic leukemia), together accounting for roughly two thirds of all AML cases [50]. Moreover, in spite of the similar antiproliferative effect attained by CX-4945 in both AML cell lines, our results and previous studies have evidenced that HL-60 cells appears to be less sensitive to CX-4945 induced apoptosis when compared to other AML cell lines (Figure S1A,B) [51]. Thus, selected cells lines not only represent major AML subtypes, but also different niches that can be found in the clinical setting considering its differential sensitivity to CK2 inhibition with CX-4945.

A

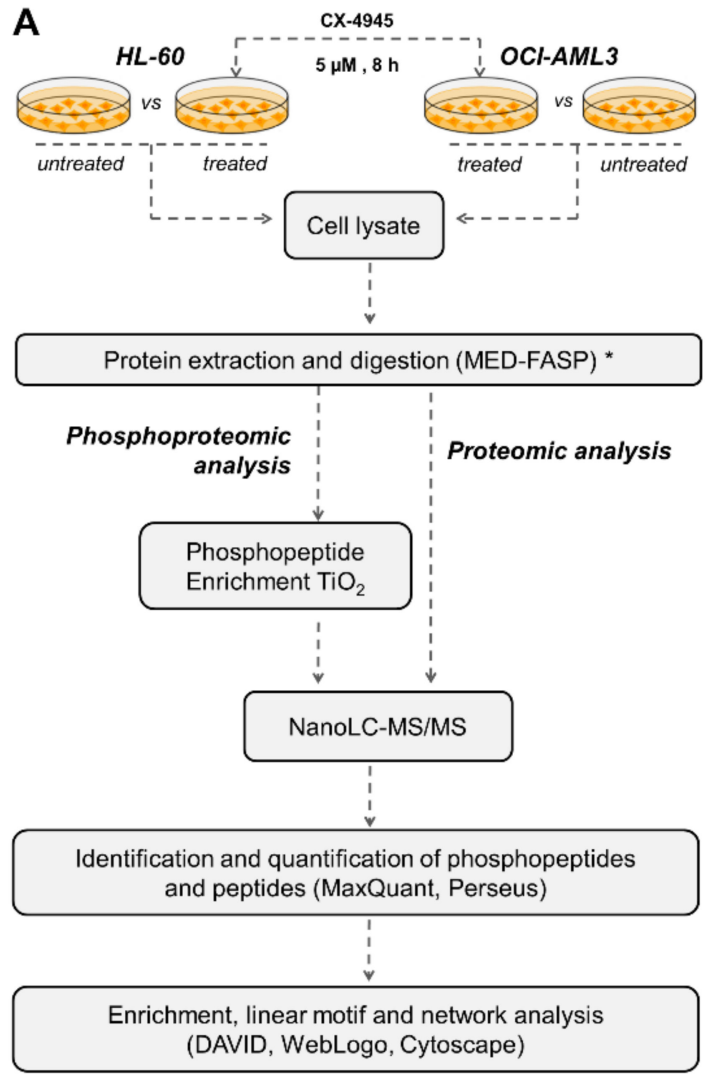

B

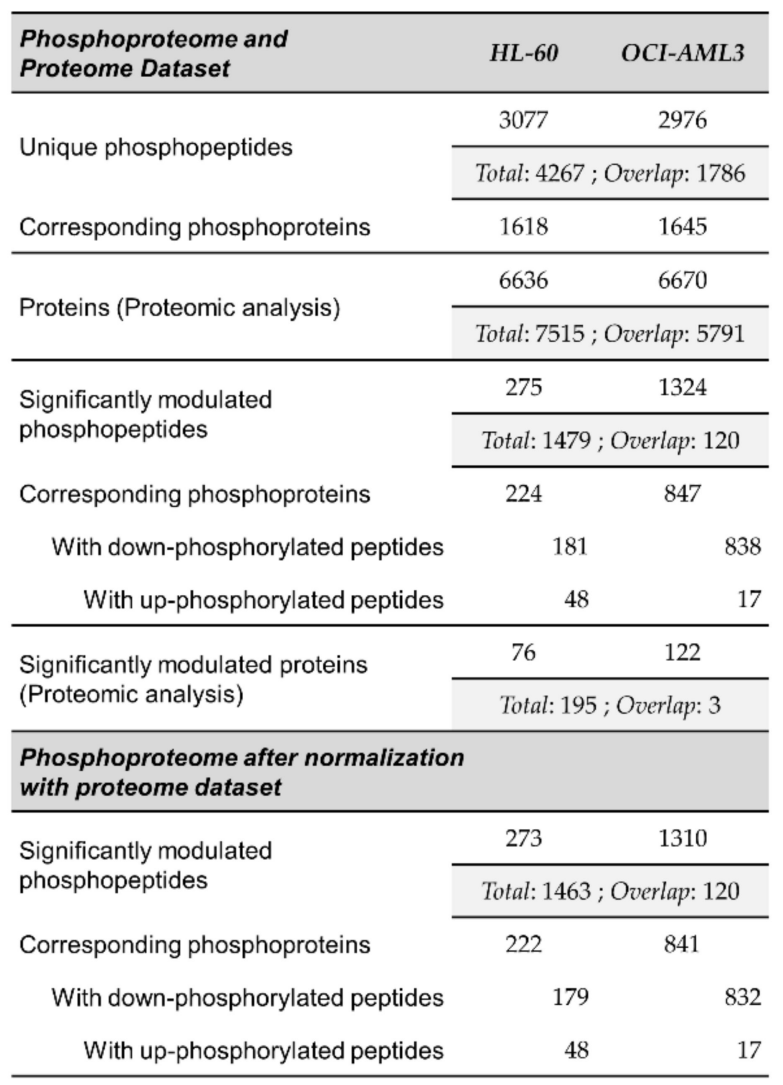

Figure 1. Phosphoproteomic and proteomic analysis of human AML cells treated with the CK2 inhibitor CX-4945: (A) Workflow for the exploration of phosphorylation changes induced in HL-60 and OCI-AML3 cells after treatment with CX-4945. Three biological replicates of each group were evaluated; (B) Number of identified and significantly modulated phosphopeptides and proteins in each AML cell line. Phosphoproteomic results are showed before and after normalization with the proteome dataset. $\left(^{*}\right)$ MED-FASP: multienzyme digestion filter-aided sample preparation [28].

Using this experimental approach, phosphoproteomic analysis of HL-60 led to identification of 3365 phosphopeptides corresponding to 3077 unique phosphopeptides (90\% pS, $9.8 \% \mathrm{pT}$ and $0.2 \% \mathrm{pY}$ ) on 1618 phosphoproteins (Figure 1B). Similarly, in OCI-AML3 cells 3177 phosphopeptides were identified, corresponding to 2976 unique phosphopeptides ( $87.8 \% \mathrm{pS}, 11.9 \% \mathrm{pT}$ and $0.3 \% \mathrm{pY}$ ) on 1645 phosphoproteins (Figure 1B). In parallel, proteomic analysis led to identification of 6636 and 6670 proteins in HL-60 and OCI-AML3, respectively (Figure 1B). On the whole, we identified a total of 4267 unique phosphopeptides and 7515 proteins, with 1786 phosphopeptides and 5791 proteins that overlapped between both AML cell lines (Figure 1B). 
Changes in phosphorylation and protein levels between untreated and CX-4945treated cells were assessed using Student's $t$ Test and $p$-value $<0.05$ was considered statistically significant. We also applied a fold-change (treated vs. control) threshold of 1.5 ( $|\mathrm{FC}| \geq 1.5$ ) to define the down- and up-regulated phosphopeptides and proteins. In HL-60 cells 275 phosphopeptides on 224 proteins were significantly modulated, while in OCI-AML3 cells the number was almost 5-fold higher with 1324 on 847 proteins (Figure 2A, Table S1). In both cellular contexts, treatment with CX-4945 elicited a global decrease of protein phosphorylation, based on the distribution of down- and up-regulated phosphopeptides in Volcano plots (Figure 2A). On the contrary, proteomic analysis indicated that in both cell lines CK2 inhibition showed no bias towards the protein down-regulation (Figure 2B, Table S2). Actually, proteome analysis evidenced that changes in phosphorylation upon CX-4945 treatment were mostly independent of protein abundance, since only eight down-regulated proteins (two in HL-60 cells and six in OCI-AML3 cells) had phosphorylation sites significantly inhibited (Figure 2B). Those proteins were not considered as differentially phosphorylated after CK2 inhibition, and consequently, were not included in the functional interpretation of the phosphoproteomic profiles.

A

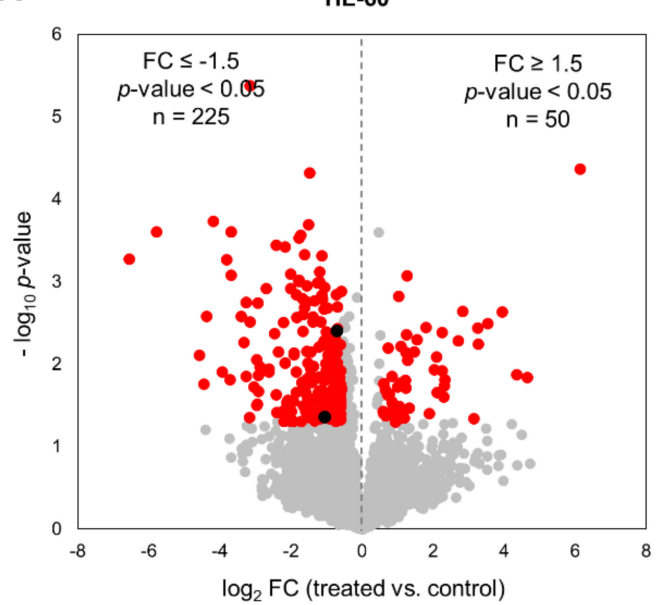

B

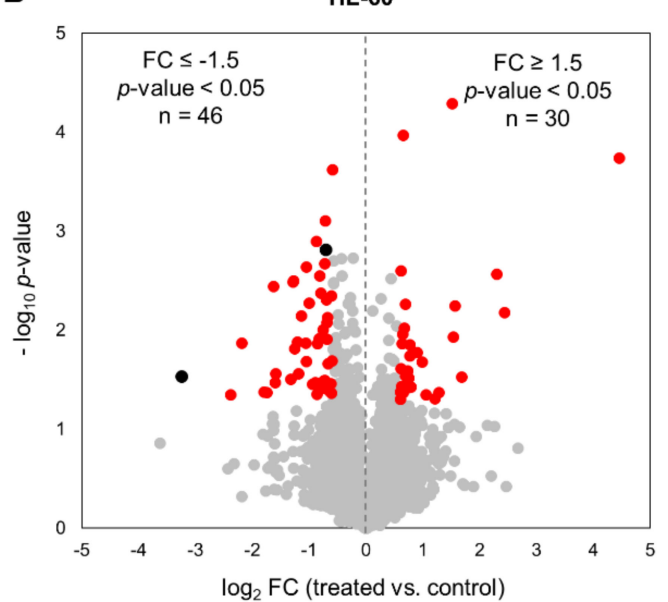

OCI-AML3

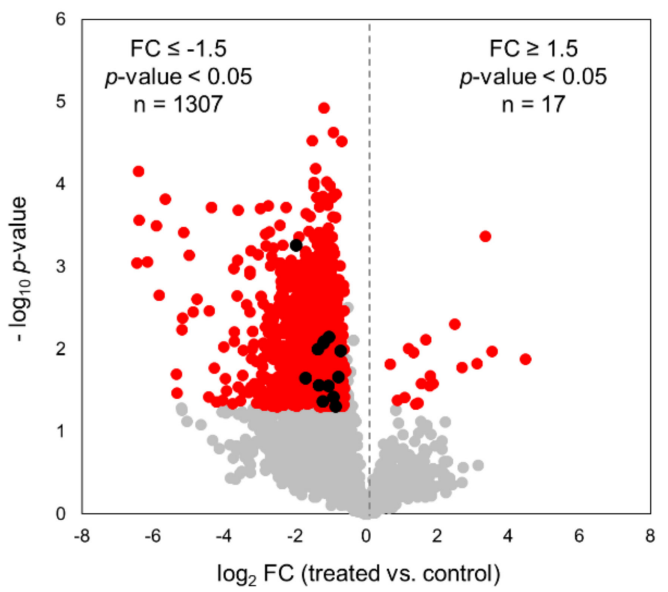

OCI-AML3

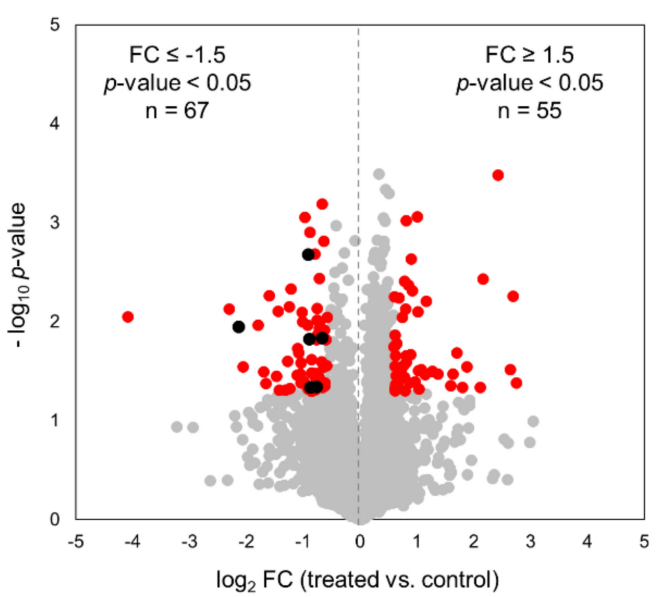

Figure 2. Phosphoproteomic and proteomic profile of human AML cells treated with the CK2 inhibitor CX-4945. Volcano plots of quantified (A) phosphopeptides and (B) proteins from HL-60 and OCI-AML3 cells after treatment with $5 \mu \mathrm{M}$ CX-4945 during $8 \mathrm{~h}$. Red points indicate those phosphopeptides/proteins that met statistical significance cut-off ( $|\mathrm{FC}| \geq 1.5$, $p$-value $<0.05)$. Additionally, black points indicate those phosphopeptides with decreased phosphorylation due to the reduction of the corresponding protein abundance in proteomic analysis (down-regulated proteins are also indicated in black). 
In summary, after normalization with the proteome dataset a total of 273 and 1310 significantly modulated phosphopeptides were identified in HL-60 and OCI-AML3 cells, respectively (Figures 1B and 2A). Remarkably, such difference indicates that CX-4945 has a more pronounced effect over the CK2-dependant signaling in OCI-AML3 cells, which suggests that the molecular perturbations induced by this inhibitor could rely on the AML cellular background. However, CX-4945 had a similar dose-dependent inhibitory effect on HL-60 and OCI-AML3 cells proliferation (Figure S1A), suggesting that despite the divergence concerning the molecular impact of protein kinase CK2 inhibition, there is no differential sensitivity of AML cells towards the overall antiproliferative effect of CX-4945.

\subsection{Enrichment Analysis of Differentially Modulated Phosphoproteins}

For better understanding of putative biological processes perturbed after CK2 inhibition in AML cells, the differentially modulated phosphoproteins were classified in terms of their biological functions using the information from the GO database [33,34]. Analysis was performed using DAVID web-based tool and GO terms list was further submitted to REViGO for redundancy reduction [35-37]. Significantly represented biological processes in both phosphoproteomics profiles include mRNA processing, regulation of viral process and protein sumoylation (Figure 3). Moreover, phosphorylation sites differentially modulated in HL-60 are located on phosphoproteins related to mRNA splicing, cellular response to DNA damage and ribosome biogenesis, while in OCI-AML3 covalent chromatin modification, nuclear transport, regulation of cell proliferation and gene expression are significantly represented (Figure 3). Of note, apoptotic signaling pathway was only identified as significantly enriched in OCI-AML3 cells. Consistently, our results and previous studies have evidenced that HL-60 cell line displays refractoriness to CX-4945 induced apoptosis (Figure S1B), probably owing to the absence of p53 protein (HL-60 cells are p53 null) and the lower CK2 protein level and activity in comparison to other AML cell lines [51]. In such studies it was demonstrated that CK2 inhibition not only triggers apoptotic cell death in AML cell lines, but also in freshly isolated blasts from AML patients [51].

HL-60

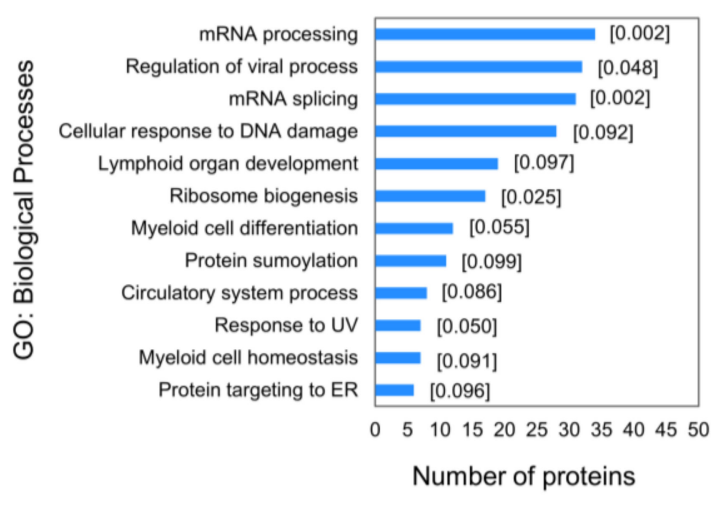

\section{OCI-AML3}

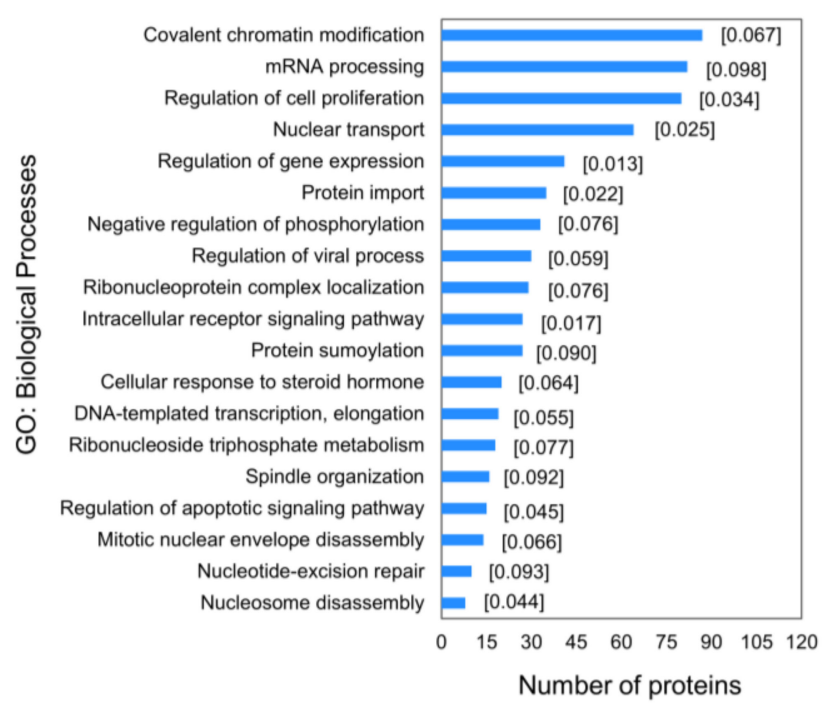

Figure 3. Enrichment analysis for differentially modulated phosphoproteins in HL-60 and OCI-AML3 cells treated with CX-4945. Biological processes significantly represented in phosphoproteomic profile were identified using annotations from GO database. The $p$-value of modified Fisher Exact Test from DAVID is placed in square brackets.

Recently, another phosphoproteomic study in non-small cell lung cancer (NSCLC) cell line NCI-H125 using the clinical-grade synthetic peptide CIGB-300, found mRNA processing and ribosome biogenesis as biological processes modulated after CK2 inhibition [26]. Protein folding, cytoskeleton organization, microtubule formation and protein ubiquiti- 
nation were also significantly modulated after treatment with CIGB-300 [26]. According with both studies, CK2 inhibition by CX-4945 or CIGB-300 modulates a common set of biological processes but also each drug exerts its own mechanism of action by modulating a unique array of phosphoproteins. Since this effect could be a consequence of the different neoplastic backgrounds explored in each study (AML and NSCLC), a phosphoproteomics study of AML cells treated with CIGB-300 is currently underway to validate our hypothesis.

Noteworthy, proteins involved in cellular response to DNA damage appeared differentially phosphorylated in HL-60 cells treated with CX-4945 (Figure 3). Accordingly, CK2-mediated phosphorylation has been verified to regulate proteins with critical role in DNA damage response and DNA repair pathways [52]. In fact, phosphoproteomic analysis of cells treated with radiomimetic compound or ionizing radiation to induce DNA double-stranded breaks showed a dynamic response for a significant number of CK2 phosphorylation motifs [53,54]. Furthermore, combination of CK2 inhibitors with DNA-targeted drugs evidenced a synergistic interaction in cancer models, owing to the suppression of DNA repair response triggered by such chemotherapeutic agents $[55,56]$. Interestingly, a number of modulated phosphorylation sites in AML cells belong to proteins implicated in regulation of viral process (Figure 3). The relevance of CK2 in viral infections has been well documented, and a number of viral and cellular proteins essential for virus replicative cycle and pathogenesis are listed as bona fide CK2 substrates [57].

On the whole, CK2 inhibition with CX-4945 impacted on a broader set of biological processes in OCI-AML3, which is in agreement with the higher number of differentially modulated phosphopeptides in this cell line (Figures 2A and 3). However, as pointed above such divergence does not impinge on the antiproliferative effect exerted by CX-4945.

\subsection{Sequence Analysis of Phosphopeptides Identified in AML Cells}

Protein kinases recognize structural and sequence motif, which in conjunction with other factors like subcellular co-localization or protein complex formation, determine their specificity [58]. Particularly, CK2 phosphorylation is specified by multiple acidic residues located mostly downstream from the phosphoacceptor amino acid, the one at position $\mathrm{n}+3$ playing the most crucial function. Besides, proline residue at position $\mathrm{n}+1$ acts as a negative determinant for protein kinase CK2 phosphorylation $[3,5]$.

In our study, approximately $21 \%$ of the phosphopeptides identified in HL-60 and OCIAML3 fulfill the CK2 consensus sequence (Figure 4A and Figure S3). This proportion of putative CK2 substrates is in accordance with previous phosphoproteomic analysis [24,59]. In HL-60 the majority of phosphopeptides (83.3\%) containing the CK2 consensus sequence were unaffected by CX-4945 treatment. Moreover, 107 phosphopeptides (16.7\%) containing the CK2 consensus sequence were significantly modulated in HL-60 treated cells, of which $14.4 \%$ had a decreased and $2.3 \%$ had an increased phosphorylation respect to non-treated cells (Figure 4A). In contrast to HL-60 cells, the majority of phosphopeptides (53.9\%) containing the CK2 consensus sequence had a decreased phosphorylation in OCI-AML3 cells treated with CX-4945, whereas $45.8 \%$ were unaffected and $0.3 \%$ had an increased phosphorylation (Figure 4A). This result reinforces the differential impact of CX-4945 over the CK2-dependent signaling, which was evidenced above by the higher number of total phosphopeptides that had a decreased phosphorylation in OCI-AML3 treated cells (1310 out of 2976) (Figure 2A). 
A

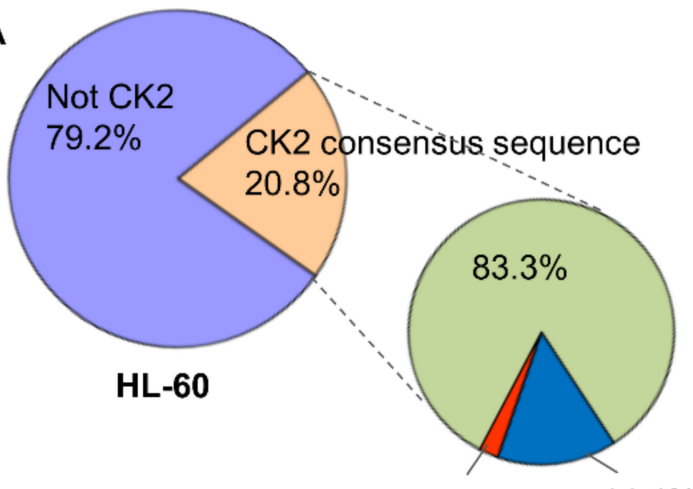

$2.3 \%$

$14.4 \%$

(*)

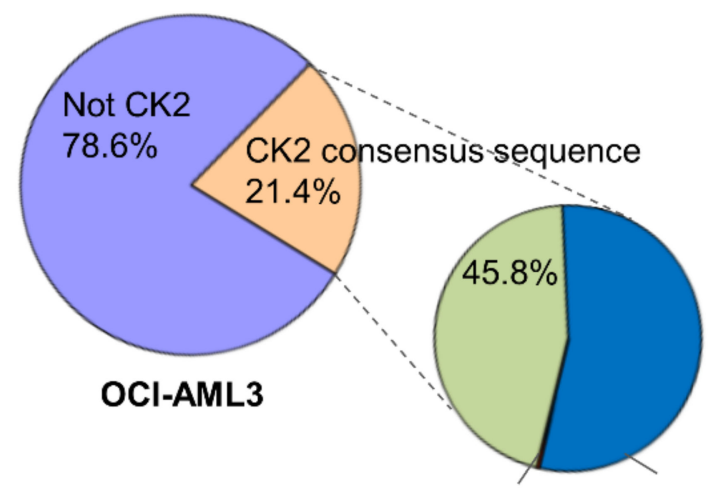

$0.3 \%$

$53.9 \%$

Unaffected phosphopeptides

Up-phosphorylated phosphopeptides

Down-phosphorylated phosphopeptides

B

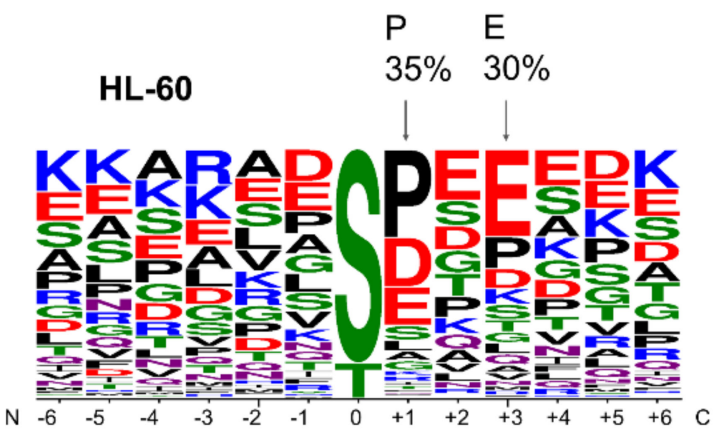

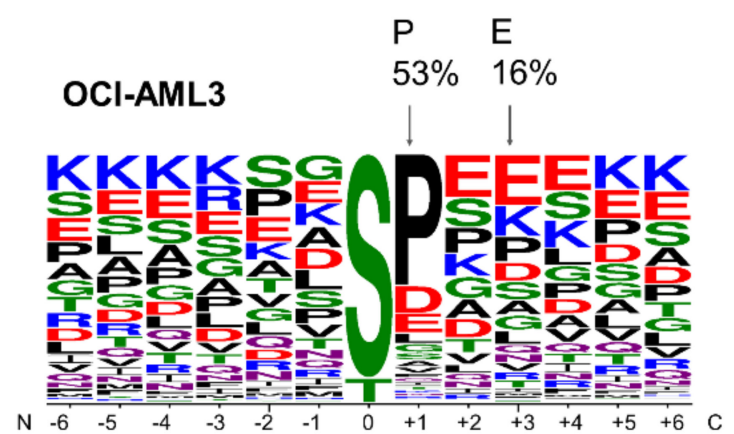

Figure 4. Sequence analysis of phosphopeptides identified in AML cells treated with the CK2 inhibitor CX-4945: (A) Pie charts show Table 60. and OCI-AML3 cells that either, contains or not the CK2 consensus sequence. For the former category, the percentage of phosphopeptides that are significantly increased or decreased, or that do not show significant changes in their phosphorylation levels are reported in lateral pie charts; (B) Sequence logos corresponding to phosphopeptides significantly down-phosphorylated in AML cells treated with CX-4945. Logos were generated using WebLogo tool and MaxQuant amino acid sequence window as input [38]. $\left(^{*}\right)$ Phosphopeptides with decreased phosphorylation due to the reduction of protein abundance were not considered as differentially regulated.

CK2 substrates have different rates of phosphorylation turnover, some of them are promptly reduced after $6 \mathrm{~h}$ of treatment with CX-4945 but others are more resistant to dephosphorylation, since requires much longer treatment times (up to $24 \mathrm{~h}$ ) and higher concentrations of the inhibitor [24]. We think that the foregoing could explain the proportion of putative CK2 phosphopeptides that resulted unaffected after $8 \mathrm{~h}$ of treatment with CX-4945 in AML cells. Even more, in C2C12 cells devoid of CK2 catalytic activity $\left(\mathrm{CK} 2 \alpha / \alpha^{\prime(-/-)}\right)$ was demonstrated that not all the phosphopeptides conforming the CK2 consensus sequence have reduced phosphorylation levels, suggesting that other kinase(s) could fulfill the phosphorylation of these sites in the absence of CK2 [27].

CK2 consensus is a quite distinctive motif where phosphoacceptor amino acid is surrounded by acidic residues [5]. As demonstrated by sequence logo analysis, the positions up- and down-stream of phosphorylated sites in peptides that significantly decreased after treatment with CX-4945 are predominantly occupied by acidic residues (Figure 4B). Furthermore, $30 \%$ and $16 \%$ of the phosphopeptides down-regulated by CX-4945 had a glutamic acid at position $n+3$ in HL-60 and OCI-AML3 cells, respectively (Figure 4B). Basic residues are less represented or practically absent at positions spanning between $n+1$ to $n+4$. All these features are consistent with the previously reported linear motif preference of CK2.

Notably, phosphopeptides containing the S/T-P motif were also down-phosphorylated in AML cells after CK2 inhibition with CX-4945 (Figure 4B). In fact, $35 \%$ and $53 \%$ of the significantly down-phosphorylated peptides had a proline at position $n+1$ in HL-60 
and OCI-AML3 cells, respectively (Figure 4B). This motif is targeted by the large and heterogeneous category of proline-directed kinases and has been previously reported that such motif is incompatible with direct phosphorylation by CK2 [60]. Thus, the downregulation of phosphopeptides containing S/T-P motif could be interpreted as off-target effect of CX-4945 or just an indirect result of CK2 inhibition, i.e., perturbations of other kinases involved in signaling networks where CK2 is also implicated. Considering that this effect has been associated not only to CX-4945, but also to others CK2 inhibitors [24-26], we reasoned that decrease in phosphorylation such phosphopeptides is just a consequence of signaling propagation following CK2 inhibition.

\subsection{Network Analysis of Kinases Associated with AML Phosphoproteomic Profiles}

To identify kinases responsible for the phosphoproteomic profile modulated in HL-60 and OCI-AML3 cells, an enzyme-substrate network was constructed using iPTMnet and KEA2 bioinformatic resources $[39,42]$. A total of 37 differentially modulated phosphopeptides in HL-60 cells ( $|\mathrm{FC}| \geq 1.5, p$-value $<0.05)$ were attributed to 31 kinases including CK2 with the higher number (10 phosphopeptides) (Figure 5, Figure S2 and Table S4). A broader picture was observed in OCI-AML3 phosphoproteome, in which 207 differentially modulated phosphopeptides were associated to 73 kinases. As expected, CK2 enzyme was again among the most represented kinases with 29 phosphopeptides (Figure 5, Figure S2 and Table S4). Kinases significantly associated with the phosphoproteomic profile were also identified using KEA2 bioinformatic tool [42]. In addition to CK2, members of the CDKs and MAPKs families like CDK1, CDK2, MAPK9 and MAPK14 were also significantly associated with the OCI-AML3 phosphoproteome (Figure S2). These results are in accordance with sequence logo analysis, which indicates that CK2 and proline-directed kinases motifs are the most frequent among the phosphopeptides down-regulated after CK2 inhibition in AML cells.

An interaction network of protein kinases associated with the phosphoproteomic profile modulated in HL-60 and OCI-AML3 cells was represented using the Metascape bioinformatic software (Figure 5) [43]. The kinome network also includes those kinases that were identified in AML cells after CK2 inhibition, with either not differentially modulated phosphopeptides (green nodes) or down-phosphorylated peptides (blue nodes). For instance, the tyrosine-phosphorylated and regulated protein kinase DYRK1A is known to promote cell proliferation and survival [61]. DYRK1A is auto-phosphorylated in S529, modification that enhances 14-3-3- $\beta$ protein binding and consequently increases the kinase catalytic activity [62]. DYRK1A S529 was found down-phosphorylated in our study, suggesting an inhibition of this kinase in HL-60 cells. In fact, the S369 of Cyclin-L2, a known DYRK1A substrate which is involved in RNA processing of apoptosis-related factors [63], was also found down-phosphorylated in HL-60 cells (Figure S2).

CK2 has direct interactions with 13 and 27 kinases related to the phosphoproteomic profile identified in HL-60 and OCI-AML3 cells, respectively (Figure 5). Such kinases include nine bona fide CK2 substrates, three of them (MAPK1, MAPK9 and CDK1) related to both phosphoproteomics profiles (Figure 5). Although none of the CK2 phosphosites belonging to these kinases were identified in the present study, the results suggest a signal propagation downstream of these proteins. For instance, CK2 phosphorylates mitogenactivated protein kinase 1 (MAPK1) at S246 and S248, such event promotes MAPK1 nuclear translocation and phosphorylation of target transcription factors [64]. A total of 19 phosphopeptides which are substrates of MAPK1 were identified down-phosphorylated in OCI-AML3 after CK2 inhibition (Figure S2). Besides, CK2 phosphorylates cyclin-dependent kinase 1 (CDK1) at S39 and regulates cell cycle [65]. Accordingly, the enzyme-substrate network evidenced an inactivation downstream of CDK1 since at least, 43 phosphosites modulated by CDK1 were down-phosphorylated in OCI-AML3 cells. Such phosphopeptides belong to proteins related to chromatin remodeling, mitotic spindle assembly, and DNA repair (Figure S2). 

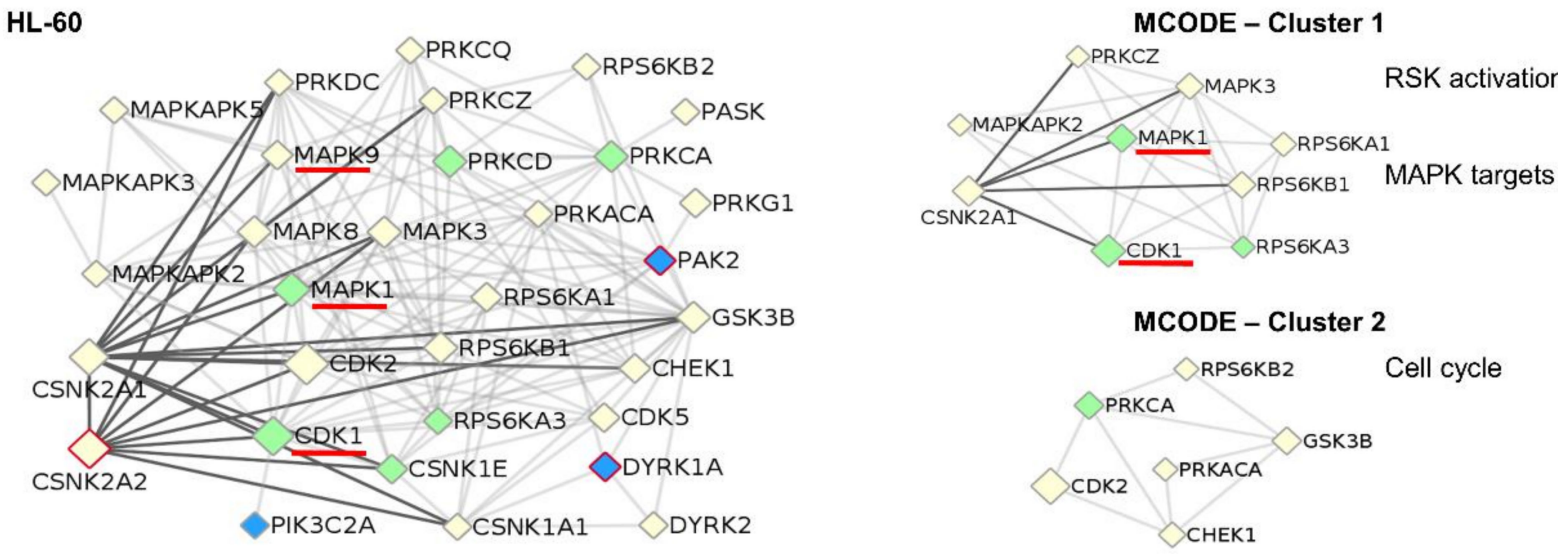

\section{OCI-AML3}

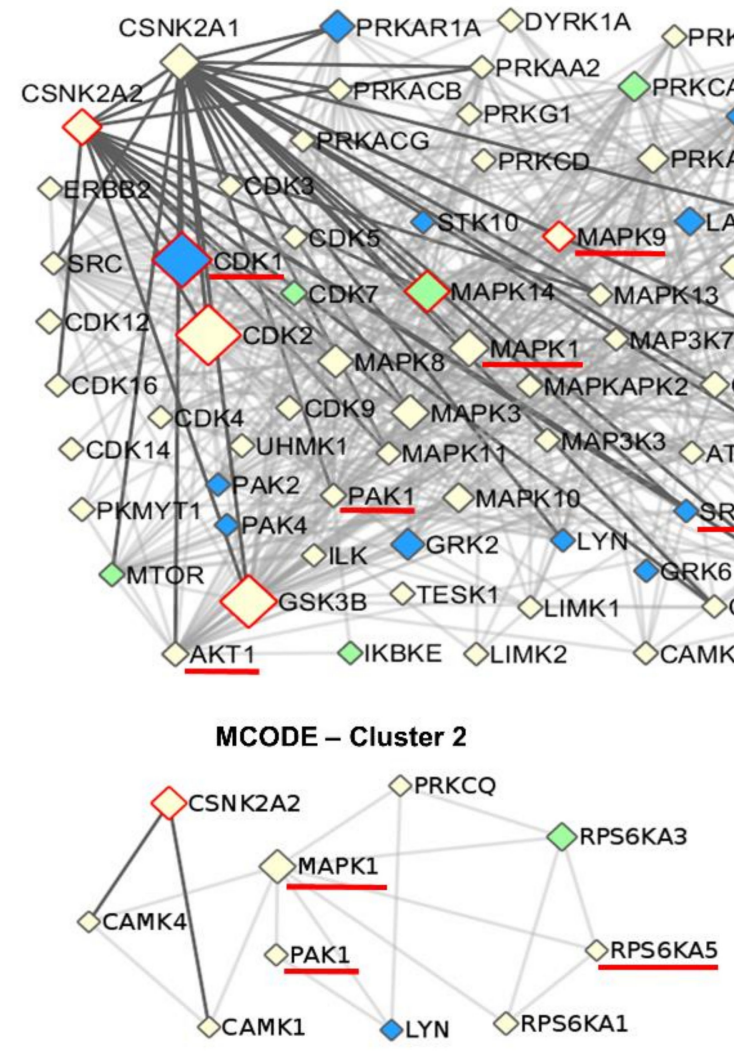

ERK/ MAPK targets

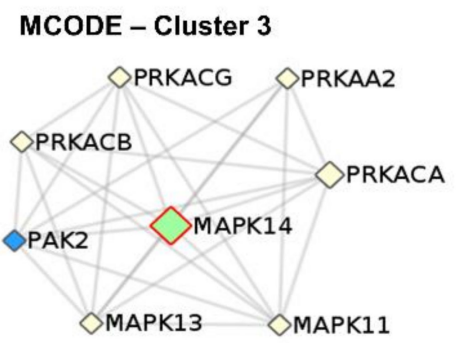

Signaling by VEGF

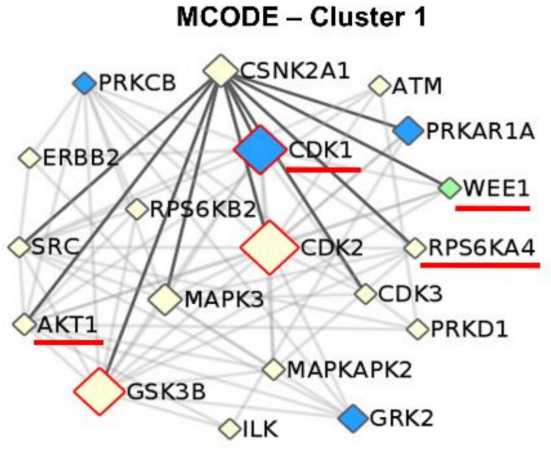

ErB signaling pathway Cell cycle

MCODE - Cluster 4

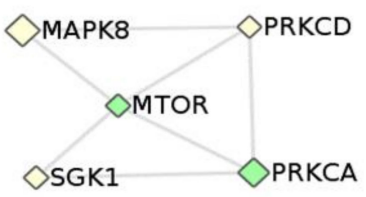

PI3K-AKT signaling pathway

\section{Node Colors}

Kinases identified with not differentially modulated phosphopeptides

Kinases identified with down-phosphorylated peptides

Figure 5. Protein-protein interaction network of kinases associated to phosphoproteomic profiles differentially modulated by CX-4945 in HL-60 and OCI-AML3 cells. Protein clusters were identified with MCODE algorithm and the related biological processes and signaling pathways are indicated. For each protein kinase the node size is proportional to the number of target phosphopeptides that appeared differentially phosphorylated in response to CK2 inhibition. Kinases that are significantly associated with the phosphoproteomic profiles, according to KEA2 results, are highlighted with a red border. In addition, kinases indicated with a red line are bona fide CK2 substrates, whereas green and blue nodes correspond to those kinases that were identified in our analysis with either not differentially modulated phosphopeptides and down-phosphorylated peptides, respectively. 
Highly connected regions in the kinome networks associated to HL-60 and OCI-AML3 phosphoproteomic profiles were identified using MCODE algorithm [44]. Clusters representing cell proliferation (MAPK targets) and cell cycle appeared as a common denominator in kinome networks from both AML cell lines (Figure 5). Accordingly, we found that CX4945 impairs AML cells proliferation and cell cycle progression (Figure S1A,B). In contrast, signaling pathways mediated by VEGF and PI3K/AKT only appeared in OCI-AML3 kinome network (Figure 5). Protein kinase CK2 it is known that up-regulates PI3K/AKT pathway, in part by phosphorylating and activating AKT [66]. To note, PI3K/AKT pathway is constitutively active and sustain viability of primary acute lymphoblastic leukemia cells (ALL), signaling alteration that results from CK2 overexpression and hyperactivation [67]. AML and ALL are hematological diseases with several features in common, and previous studies have showed that the antineoplastic effect of CX-4945 in both malignancies is mediated by attenuation of the PI3K/AKT pathway [51,68-70]. Accordingly, we found a number of AKT substrates down-phosphorylated in OCI-AML3 cells after CK2 inhibition with CX-4945, whereas in HL-60 cells the PI3K/AKT pathway did not appeared significantly represented in our analysis, explaining perhaps its refractoriness to CX-4945-induced apoptosis. Such findings are in agreement with Annexin V/PI staining and immunodetection of phosphorylation status and total protein levels of PI3K/AKT mediators (Figure S1C,D).

Importantly, previous phosphoproteomic results from primary AML cells have indicated that at the diagnosis time, patients that relapse after chemotherapy had a higher CK2, MAPK and CDK activity in comparison with patients which have free-relapse evolution [22]. However, the high CK2 activity at diagnosis of relapsed patients was no longer observed in chemoresistant cells [23]. Aasebø et al. pointed out that the proteome and phosphoproteome profiles changed considerably from the first diagnosis to the first relapse, therefore CK2 could be important in inducing treatment-resistant clones but dispensable for the survival of clones that already have become resistant to therapy [23]. Remarkably, in our study substrates of CK2, MAPKs and CDKs were found down-phosphorylated after CX-4945 treatment of AML cell lines, being MAPKs and CDKs signaling modulation probably a down-stream consequence of CK2 inhibition (Figure 5, Table S4).

\subsection{Identification of CK2 Substrates Modulated by CX-4945 in AML Cells}

Besides the bona fide CK2 substrates annotated in iPTMnet and KEA databases [39,42], additional candidate $\mathrm{CK} 2$ substrates in AML cells were searched. According to the presence of the CK2 consensus sequence, $39 \%$ and $26 \%$ of all differentially modulated phosphopeptides on HL-60 and OCI-AML3 respectively, could be putative CK2 substrates responsive to CX-4945. However, phosphosites recognized by other protein kinases like Ser/Thrprotein kinase Chk1 or cAMP dependent protein kinase catalytic subunit alpha (PKACA) could contain an acidic amino acid at position $n+3$ (Figure S3). Indeed, we observed that arginine is frequent at position $\mathbf{n}-3$ from the phosphorylated residue (Figure 4 ), a motif that is recognized by basophilic kinases [59]. Therefore, we search for additional evidences in support phosphoproteins containing the CK2 consensus sequence as candidate CK2 substrates.

First, differentially phosphorylated proteins identified in AML cells were searched as candidate CK2 substrates using NetworKIN database [45]. Such database includes enzymesubstrate interactions predicted not only based on the consensus sequence recognized by the enzyme, but also using a protein association network to model the context of substrates and kinases, which improves the prediction accuracy [45]. Second, the phosphoproteomic profile differentially modulated in AML cells after CK2 inhibition was compared with a dataset of high confidence CK2 substrates reported by Bian et al. [46]. These authors identified in vitro CK2 substrates by combining kinase reaction on immobilized proteomes with quantitative phosphoproteomics, and to reduce false positive results compared in vitro phosphosites with in vivo phosphorylation sites reported in databases [46]. Lastly, the differentially modulated phosphoproteins that interact with CK2 were searched using 
Metascape, which performed interactome analysis based on integrative protein-protein interactions databases like InWeb_IM and OmniPath [43].

Taking into account the four levels of predictions (CK2 consensus sequence, NetworKIN prediction, CK2 substrates predicted by Bian et al. [46] and interaction with CK2) we identified a total of 117 and 359 candidate CK2 substrates differentially modulated after CK2 inhibition in HL-60 and OCI-AML3 cells, respectively (Table S5). This dataset was filtered out to find those substrates that had the concomitant occurrence of two or more criteria associated to CK2 phosphorylation. Applying this workflow, in HL-60 cells 64 phosphosites on 53 proteins were identified as the most reliable CK2 substrates modulated after treatment with CX-4945, whereas 168 phosphosites on 120 proteins were identified in OCI-AML3 cells (Figure 6, Table S5). The list includes those CK2 substrates previously confirmed as bona fide according to iPTMnet and KEA databases $[39,42]$.

Remarkably, for the $67 \%$ and $71 \%$ of the high confidence CK2 substrates modulated in HL-60 and OCI-AML3 cells, respectively, any related enzyme was annotated in iPTMnet database. Besides, to our knowledge the phosphosites S280 of coilin protein and T180 of inosine-5'-monophosphate dehydrogenase 2 (IMPDH2) are reported for the first time. Coilin protein is an integral component of Cajal bodies-subnuclear compartments, whereas IMPDH2 catalyzes the first and rate-limiting step for de novo guanine nucleotide biosynthesis pathway [71,72]. Interestingly, both proteins regulate cell growth and have been related to malignant transformation [72,73]. However, validation of coilin S280 and IMPDH2 T180 as phosphorylation sites targeted by CK2 and the biological roles of such post-translational modifications need further experimentation.

\subsection{Functional Characterization of CK2 Substrates Identified in AML Cells}

Phosphoproteins identified as candidate CK2 substrates are related to transcription, mRNA splicing, rRNA processing, translation, DNA repair and cell cycle in both AML cells lines (Figure 6). However, the number of potential CK2 substrates differentially modulated after CK2 inhibition is higher in OCI-AML3 cells than in HL-60 cells. As pointed before, this could explain the different sensitivity to CX-4945 cytotoxic effect of HL-60 cells in comparison to other AML cell lines [51]. In fact, we identified candidate CK2 substrates related to apoptosis only in the phosphoproteomic profile of OCI-AML3 cells (Figure 6). This subset includes three tumor suppressors: erythrocyte membrane protein band 4.1 like 3 (EPB41L3 S88), the programmed cell death 4 protein (PDCD4 S457) and the death inducer-obliterator 1 (DIDO1 S809). However, the effect of CK2-mediated phosphorylation for the function of these proteins remains to be determined.

CK2 inhibition in AML cells could impact the transcriptional machinery by modulating the phosphorylation of several candidate substrates. Such CK2 candidate substrates in OCI-AML3 phosphoproteomic profile are centered around the RNA polymerase II subunit A (POLR2A) according to protein-protein interactions gathered from STRING database (Figure 6) [47]. Three components of the PAF1 complex which interacts with RNA polymerase II during transcription were identified as candidate CK2 substrates: RNA polymerase II-associated factor 1 homolog (PAF1 S394), RNA polymerase-associated protein LEO1 (LEO1 S296, S630, S658 and T629) and RNA polymerase-associated protein CTR9 homolog (CTR9 T925). PAF1 complex is required for transcription of Hox and Wnt target genes [74]. Therefore, down-phosphorylation of these candidate substrates could modulate the Wnt signaling pathway. Supporting this hypothesis, previous studies highlights that CK2 is a positive regulator of Wnt signaling pathway and CK2 inhibition by CX-4945 has been associated with $\mathrm{Wnt} / \beta$-catenin inhibition $[75,76]$. 


\section{HL-60 Transcription}

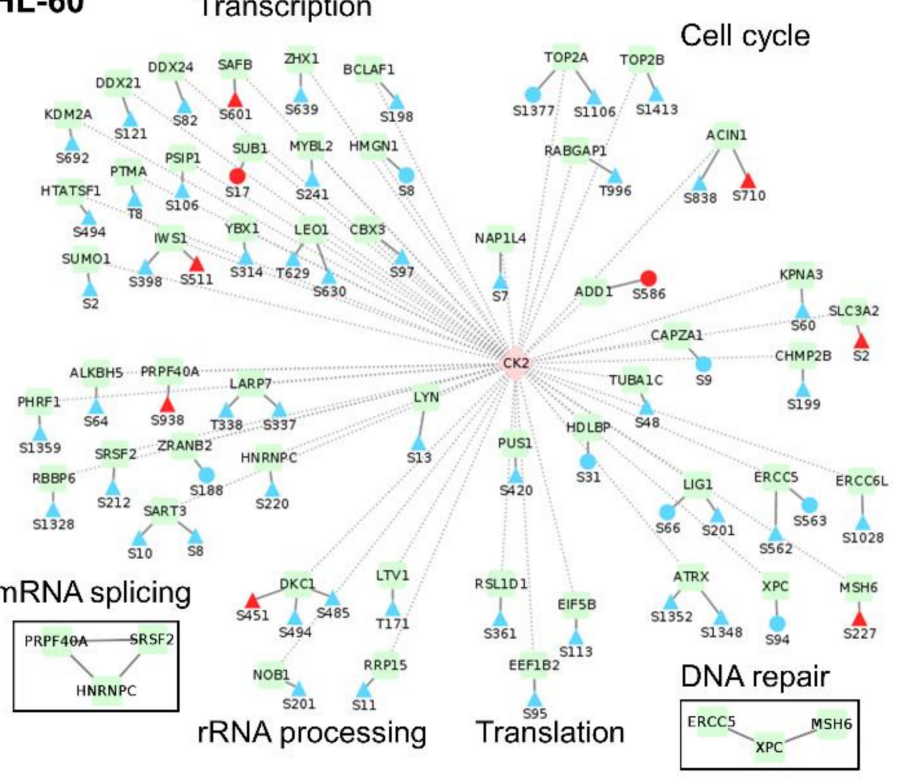

\section{Node Shapes}

$\triangle$ Kinases

$\square$ Substrates

$\triangle$ Predicted CK2 phosphoaceptor sites

Bona fide CK2 phosphoaceptor sites

\section{Node Colors}

Up-phosphorylated peptides

Down-phosphorylated peptides

\section{OCI-AML3}

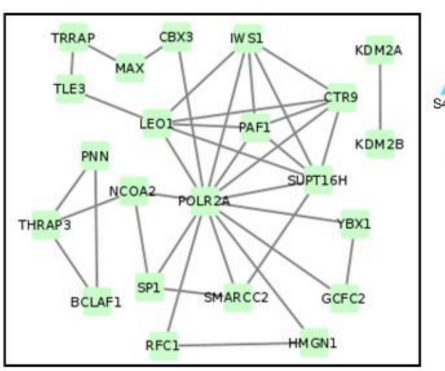

Transcription

\section{Cell cycle}

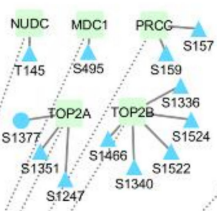

\section{Apoptosis}

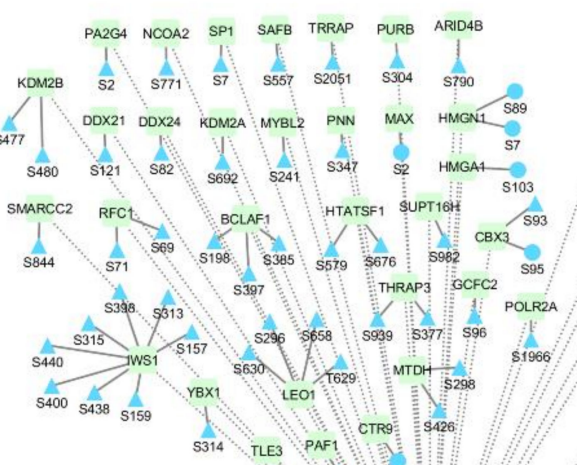

+. 5394
PDCD4 EPBA1L3

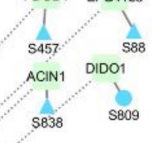

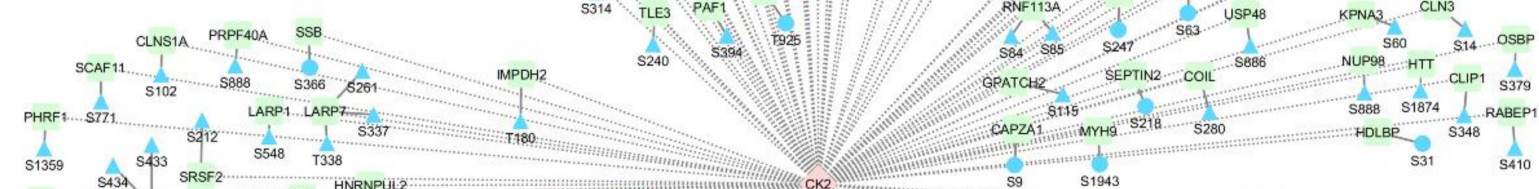

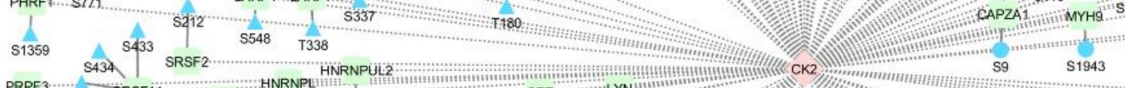

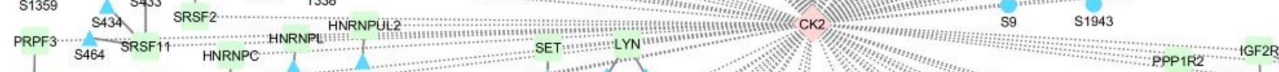

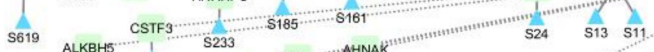

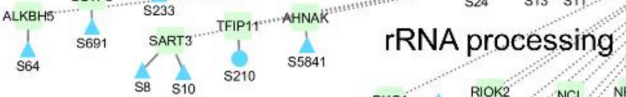

mRNA splicing

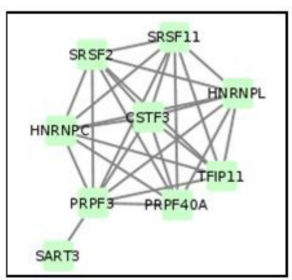

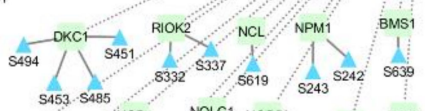
NOB1 NOLC1 NOP5B EXOSC9 LTV1

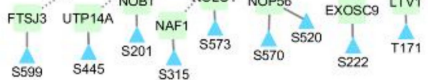

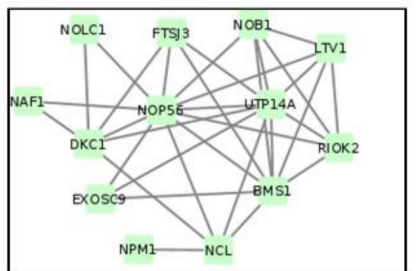

Translation

RSLID EIFAB EIF3N EIF3C S361 $\$ 445$ \$ $\$ 498, \$ 11, \quad$ S39 EFSB EIF2S2 ABCF1 EEF1B2 EEF1D

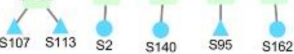

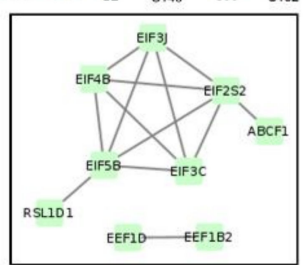

HSPH1 NAP1L4 CANX _ 17 S564 $\$ 554$ HSP9OAB1 ST13 S226 HSPOOAA1 I

Figure 6. Network of CK2 substrates differentially modulated after CK2 inhibition with CX-4945 in AML cells. For each substrate, the phosphoacceptor sites (bona fide and predicted) for CK2-mediated phosphorylation and its modulation after incubation with CX-4945 are indicated. Phosphoproteins are grouped according to related biological processes annotated in GO database and squares representing protein-protein interactions networks retrieved from STRING database are shown. 
Substrates related to transcription include bona fide CK2 targets such as the nonhistone chromosomal protein HMG-14 (HMGN1) and the high mobility group protein HMG-I/HMG-Y (HMGA1) [77-79]. The phosphorylation level of both proteins (HMGN1 S7, S8, S89; HMGA1 S103) decreased after CK2 inhibition by CX-4945 (Figure 6). Importantly, AML patients that relapsed after chemotherapy have an increased phosphorylation level of HMGN1 S7 [22]. In general HMG proteins modulate chromatin and nucleosome structure, participate in transcription, replication, DNA repair, and extracellular HMGN1 has been described to function as an alarmin that contributes to the generation of innate and adaptative immune responses [80,81]. The biological effect of CK2 phosphorylation of HMGN1 and HMGA1 is currently unknown, although, previous studies suggest that phosphorylation of HMGN1 could interfere with its nuclear localization [78].

The most densely down-phosphorylated protein among the candidate CK2 substrates is the protein IWS1 homolog (IWS1) which was identified with eight phosphopeptides in OCI-AML3 cells (Figure 6). This protein recruits a number of mRNA export factors and histone modifying enzymes to the RNA polymerase II elongation complex and modulates the production of mature mRNA transcripts $[82,83]$. As illustrated by Figure 6, several candidate CK2 substrates related to mRNA splicing were down-phosphorylated after CK2 inhibition in AML cells, including members of the spliceosome complex. Among those proteins are heterogeneous nuclear ribonucleoproteins (HNRNPC, HNRNPL), serine and arginine rich splicing factors (SRSF2, SRSF11) and pre-mRNA processing factors (PRPF3 and PRPF40A) (Figure 6). In particular, CK2 phosphorylation of heterogeneous nuclear ribonucleoproteins $\mathrm{C} 1 / \mathrm{C} 2$ (HNRNPC) it known that regulates its binding to mRNA $[84,85]$. In agreement with our results, was previously demonstrated that CK2 inhibition by quinalizarin and CIGB-300 modulates a subset of CK2 substrates related to transcription, RNA processing and mRNA splicing $[24,26]$. To note that at the time of diagnosis, phosphoproteins containing CK2 phosphoacceptor sites and related to RNA processing have an increased phosphorylation level in relapse AML patients when compared to those which have a relapse-free evolution [22]. Another phosphoproteomic study comparing pairing samples of AML patients at the time of diagnosis and first relapse found that also RNA-splicing and -binding proteins were up-phosphorylated at first relapse [23].

CK2 phosphorylation of proteins related to rRNA processing and translation has been well documented [3]. Among the proteins probably subject to CK2 regulation in AML cells are members of the nucleolar ribonucleoprotein complex (NAF1 S315; DKC1 S451, S453, S485, S494; NOP56 S520, S570) (Figure 6). According to information gathered from STRING database [47], such proteins interacts with phosphoproteins related to ribosome biogenesis (RIOK2 S332, S337; BMS1 S639; LTV1 T171) which were identified mainly in OCI-AML3 cells (Figure 6). The effect of CK2 regulation of these proteins remains to be elucidated. However, the results highlight the important role of CK2 in regulating protein biosynthesis to support the high proliferative rate of tumor cells. In line with this result, a cluster of eukaryotic translation initiation factors (EIF) was down-phosphorylated after CK2 inhibition (Figure 6). This cluster contains two members of the EIF3 complex: EIF3J S11 and EIF3C S39. EIF3J is a known CK2 substrate and its phosphorylation on S127 promotes assembly of EIF3 complex and activation of the translational initiation machinery [86]. Besides, CK2 phosphorylates EIF2 $\beta$ on S2, a phosphopeptide also identified in our study, and such modification stimulates EIF2 $\beta$ function in protein synthesis [87]. Down-phosphorylation of proteins related to the translational machinery after CK2 inhibition could add a beneficial impact at the clinical evolution of AML patients, since protein translation has been associated with increased relapse risk [22,23].

Another function attributed to CK2 is the regulation of the cellular DNA damage response [52]. After CK2 inhibition in AML cells, the biological process of DNA repair appeared significantly represented in the phosphoproteomic profiles (Figure 3). A recent study demonstrated that proteins related to DNA repair have increased phosphorylation levels in relapse AML patients [22]. Among those phosphoproteins associated with such unfavorable chemotherapy outcome, we identified in our study that treatment of AML 
cells with CX-4945 down-phosphorylates TRIM28 S19, TP53BP1 S523/S525 and LIG1 S66, this latter a known CK2 substrate (Table S1) [88]. Besides, others known and putative CK2 substrates related to DNA repair were also found down-phosphorylated in our study, like the DNA damage recognition and repair protein (XPC S94) (Figure 6). In particular, CK2 phosphorylation of XPC at S94 promotes recruitment of ubiquitinated XPC to the chromatin which is important for nucleotide excision repair following ultraviolet induced DNA damage [89]. Previous studies demonstrated that CK2 inhibition by CX-4945 inactivates the function of other essential DNA repair proteins, supporting the synergistic interaction of this inhibitor with chemotherapeutic agents that induce DNA damage [55].

Worthy of note, we identified members of the heat shock protein 90 (HSP90) chaperone proteins differentially modulated in OCI-AML3 phosphoproteomic profile. CK2 mediated phosphorylation of HSP90 is required for its chaperone activity toward client kinases, some of them involved in human cancers [90,91]. Phosphosites from HSP90-alpha (HSP90AA1 S263) and HSP90-beta (HSP90AB1 S226) were both down-phosphorylated after CK2 inhibition in OCI-AML3 cells (Figure 6). Thus, modulation of HSP90 by CX-4945 in OCI-AML3 cells could be in part responsible for the signal propagation downstream of CK2 inhibition and the pronounced effect over the kinome network in this cell line. In agreement with our findings, besides attenuation of PI3K/AKT pathway, disruption of unfolded protein response (UPR) have also been pointed as a mediator of CX-4945-induced apoptosis in ALL cell lines and primary lymphoblasts $[69,70]$. Importantly, in such effect the reduction of chaperoning activity of HSP90 appears to play a critical role $[69,70]$. Moreover, in multiple myeloma (MM) cells, another hematological malignancy having common features with AML, has been documented that CK2 inhibition causes apoptotic cell death through alterations of the UPR pathway [92].

In summary we found that the phosphoproteomic profiles modulated after CK2 inhibition with CX-4945 in AML cell lines, contain protein mediators of signaling pathways and biological processes previously described in primary AML cells (Figure 7) [22,23,51,68]. Therefore, our findings, in conjunction with Quotti Tubi et al. results and AML patients phosphoproteomic data from Aasebø et al., support the rationale of protein kinase CK2 pharmacologic inhibition for AML targeted therapy, an approach that could significantly improve the outcome in AML therapeutics.

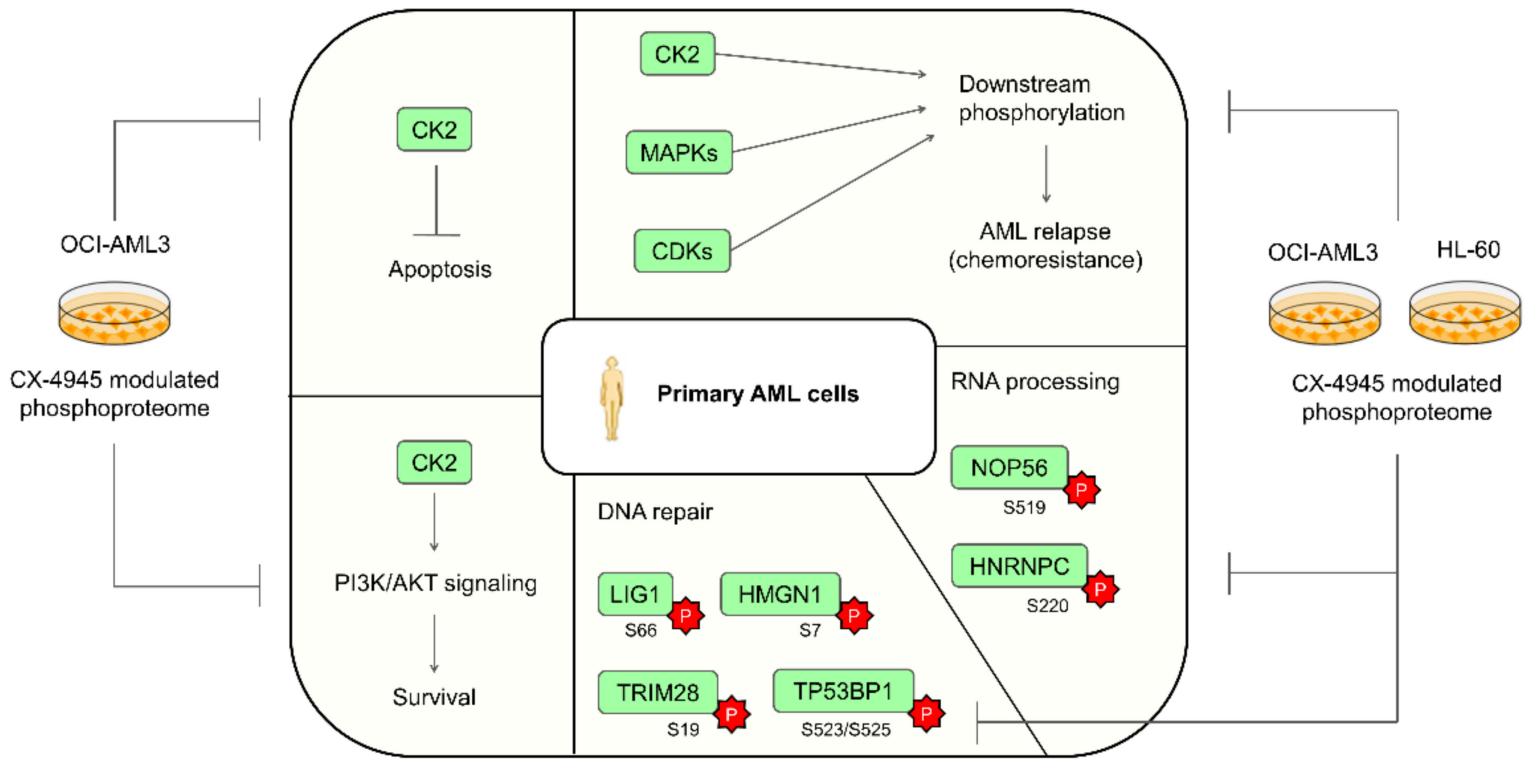

Up-phosphorylated

Figure 7. Signaling pathways and biological processes deregulated in primary AML cells and modulated by the CK2 inhibitor CX-4945 in AML cell lines. Phosphoproteins up-regulated in primary AML cells and down-phosphorylated in CX-4945-treated AML cells are indicated. 


\section{Conclusions}

Our study provides the first quantitative phosphoproteomic analysis exploring the molecular impact of the ATP-competitive CK2 inhibitor CX-4945 in human cell lines representing two differentiation stages and major AML subtypes. Here, we identified a total of 273 and 1310 unique phosphopeptides as significantly modulated in HL-60 and OCI-AML3 cells, respectively. Modulated phosphopeptides are mainly related to mRNA processing and splicing, response to DNA damage stimulus, protein sumoylation and regulation of viral processes. In addition, the network analysis illustrated how the relationship of CK2 with other kinases could orchestrate the perturbation of AML cells phosphoproteome. In this complex cellular response, phosphorylation mediated by other kinases besides CK2 could be interpreted as a consequence of signal propagation downstream of CK2 inhibition, rather than off-targets effects. Additionally, using database mining and prediction tools, in HL-60 cells we identified 64 phosphosites on 53 proteins as high confidence CK2 substrates responsive to CX-4945, whereas 168 phosphosites on 120 proteins were identified in OCI-AML3 cells. Such substrates not only explain the variety of cellular effects exerted by CX-4945, but also reinforce the instrumental role of protein kinase CK2 in AML biology. Besides, selected cells lines not only represent two major AML subtypes, but also different niches that can be found in the clinical practice if we consider the differential sensitivity to CK2 inhibition with CX-4945 displayed by these cell lines. Finally, our results, in conjunction with previous findings in primary AML cells, support the suitability of using CK2 inhibitors for AML targeted therapy, a pharmacologic approach that could significantly improve the outcome in AML patients.

Supplementary Materials: Supplementary materials can be found at https://www.mdpi.com/ 2073-4409/10/2/338/s1. Figure S1. CK2 inhibitor CX-4945 impairs proliferation and viability of AML cells. Figure S2. Enzyme-substrate network of differentially modulated phosphopeptides identified in AML cells using annotations from iPTMnet and KEA2. Figure S3. Sequence logos of phosphopeptides targeted by protein kinases representing five kinase groups (CAMK, Atypical, CK1, AGC and other) in the human kinome. Table S1. Phosphoproteomic profile of AML cells treated with the CK2 inhibitor CX-4945. Table S2. Proteins differentially modulated in AML cells treated with the CK2 inhibitor CX-4945. Table S3. Phosphopeptides that fulfill the CK2 consensus sequence in AML phosphoproteomic profiles. Table S4. Data mining of kinases associated to differentially phosphorylated peptides in AML phosphoproteomic profiles. Table S5. Candidate CK2 substrates differentially modulated in AML cells treated with CX-4945. Supplementary Methods. AlamarBlue Assay, Cell Cycle Analysis, Annexin V/PI Staining, Western Blot.

Author Contributions: Conceptualization, S.E.P., Y.P., Y.R. and L.J.G.; methodology, J.R.W. and K.Z.; software, O.G.; formal analysis, M.R., A.R.-U. and A.C.R.; investigation, V.B. and G.V.P.; data curation, V.B.; writing—original draft preparation, M.R. and A.R.-U.; writing—review and editing, A.C.R. and G.V.P.; supervision, S.E.P. and Y.P.; project administration, S.E.P.; funding acquisition, J.R.W. All authors have read and agreed to the published version of the manuscript.

Funding: This work was supported by the German Ministry of Education and Science (01DN18015) and the Max-Planck Society for the Advancement of Science. The APC was funded by "The Science and Technology Innovation Program of Hunan Province", China, grant number 2020RC5035.

Institutional Review Board Statement: Not applicable.

Informed Consent Statement: Not applicable.

Data Availability Statement: Data is contained within the article or Supplementary Materials.

Acknowledgments: We thank Igor Parón for the support in mass spectrometry analysis.

Conflicts of Interest: The authors declare no conflict of interest. 


\section{References}

1. Cohen, P. Protein kinases-The major drug targets of the twenty-first century? Nat. Rev. Drug Discov. 2002, 1, 309-315. [CrossRef]

2. Ardito, F.; Giuliani, M.; Perrone, D.; Troiano, G.; Lo Muzio, L. The crucial role of protein phosphorylation in cell signaling and its use as targeted therapy (Review). Int. J. Mol. Med. 2017, 40, 271-280. [CrossRef]

3. Meggio, F.; Pinna, L.A. One-thousand-and-one substrates of protein kinase CK2? FASEB J. Off. Publ. Fed. Am. Soc. Exp. Biol. 2003, 17, 349-368. [CrossRef]

4. Litchfield, D.W. Protein kinase CK2: Structure, regulation and role in cellular decisions of life and death. Biochem. J. 2003, 369, 1-15. [CrossRef]

5. Salvi, M.; Sarno, S.; Cesaro, L.; Nakamura, H.; Pinna, L.A. Extraordinary pleiotropy of protein kinase CK2 revealed by weblogo phosphoproteome analysis. Biochim. Biophys. Acta 2009, 1793, 847-859. [CrossRef] [PubMed]

6. Nuñez de Villavicencio-Diaz, T.; Rabalski, A.J.; Litchfield, D.W. Protein kinase CK2: Intricate relationships within regulatory cellular networks. Pharmaceuticals 2017, 10. [CrossRef]

7. Trembley, J.H.; Wang, G.; Unger, G.; Slaton, J.; Ahmed, K. Protein kinase CK2 in health and disease: CK2: A key player in cancer biology. Cell. Mol. Life Sci. CMLS 2009, 66, 1858-1867. [CrossRef] [PubMed]

8. Chua, M.M.; Ortega, C.E.; Sheikh, A.; Lee, M.; Abdul-Rassoul, H.; Hartshorn, K.L.; Dominguez, I. CK2 in cancer: Cellular and biochemical mechanisms and potential therapeutic target. Pharmaceuticals 2017, 10. [CrossRef]

9. Qiao, Y.; Chen, T.; Yang, H.; Chen, Y.; Lin, H.; Qu, W.; Feng, F.; Liu, W.; Guo, Q.; Liu, Z.; et al. Small molecule modulators targeting protein kinase CK1 and CK2. Eur. J. Med. Chem. 2019, 181, 111581. [CrossRef] [PubMed]

10. Li, C.; Liu, X.; Lin, X.; Chen, X. Structure-activity relationship of 7 flavonoids on recombinant human protein kinase CK2 holoenzyme. Zhong Nan Da Xue Xue Bao Yi Xue Ban J. Cent. South Univ. Med. Sci. 2009, 34, $20-26$.

11. Perea, S.E.; Reyes, O.; Puchades, Y.; Mendoza, O.; Vispo, N.S.; Torrens, I.; Santos, A.; Silva, R.; Acevedo, B.; López, E.; et al. Antitumor effect of a novel proapoptotic peptide that impairs the phosphorylation by the protein kinase 2 (casein kinase 2). Cancer Res. 2004, 64, 7127-7129. [CrossRef] [PubMed]

12. Laudet, B.; Barette, C.; Dulery, V.; Renaudet, O.; Dumy, P.; Metz, A.; Prudent, R.; Deshiere, A.; Dideberg, O.; Filhol, O.; et al. Structure-based design of small peptide inhibitors of protein kinase CK2 subunit interaction. Biochem. J. 2007, 408, 363-373. [CrossRef]

13. Slaton, J.W.; Unger, G.M.; Sloper, D.T.; Davis, A.T.; Ahmed, K. Induction of apoptosis by antisense CK2 in human prostate cancer xenograft model. Mol. Cancer Res. MCR 2004, 2, 712-721.

14. Perea, S.E.; Baladrón, I.; Valenzuela, C.; Perera, Y. CIGB-300: A peptide-based drug that impairs the Protein Kinase CK2-mediated phosphorylation. Semin. Oncol. 2018, 45, 58-67. [CrossRef]

15. Zakharia, K.; Miyabe, K.; Wang, Y.; Wu, D.; Moser, C.D.; Borad, M.J.; Roberts, L.R. Preclinical in vitro and in vivo evidence of an antitumor effect of CX-4945, a casein kinase II inhibitor, in cholangiocarcinoma. Transl. Oncol. 2019, 12, 143-153. [CrossRef]

16. Kim, J.S.; Eom, J.I.; Cheong, J.W.; Choi, A.J.; Lee, J.K.; Yang, W.I.; Min, Y.H. Protein kinase CK2alpha as an unfavorable prognostic marker and novel therapeutic target in acute myeloid leukemia. Clin. Cancer Res. Off. J. Am. Assoc. Cancer Res. 2007, 13, 1019-1028. [CrossRef]

17. Döhner, H.; Weisdorf, D.J.; Bloomfield, C.D. Acute myeloid leukemia. N. Engl. J. Med. 2015, 373, 1136-1152. [CrossRef] [PubMed]

18. Piazza, F.; Manni, S.; Ruzzene, M.; Pinna, L.A.; Gurrieri, C.; Semenzato, G. Protein kinase CK2 in hematologic malignancies: Reliance on a pivotal cell survival regulator by oncogenic signaling pathways. Leukemia 2012, 26, 1174-1179. [CrossRef]

19. Buontempo, F.; McCubrey, J.A.; Orsini, E.; Ruzzene, M.; Cappellini, A.; Lonetti, A.; Evangelisti, C.; Chiarini, F.; Evangelisti, C.; Barata, J.T.; et al. Therapeutic targeting of CK2 in acute and chronic leukemias. Leukemia 2018, 32, 1-10. [CrossRef] [PubMed]

20. Prins, R.C.; Burke, R.T.; Tyner, J.W.; Druker, B.J.; Loriaux, M.M.; Spurgeon, S.E. CX-4945, a selective inhibitor of casein kinase-2 (CK2), exhibits anti-tumor activity in hematologic malignancies including enhanced activity in chronic lymphocytic leukemia when combined with fludarabine and inhibitors of the B-cell receptor pathway. Leukemia 2013, 27, 2094-2096. [CrossRef]

21. Pan, C.; Olsen, J.V.; Daub, H.; Mann, M. Global effects of kinase inhibitors on signaling networks revealed by quantitative phosphoproteomics. Mol. Cell. Proteom. MCP 2009, 8, 2796-2808. [CrossRef]

22. Aasebø, E.; Berven, F.S.; Bartaula-Brevik, S.; Stokowy, T.; Hovland, R.; Vaudel, M.; Døskeland, S.O.; McCormack, E.; Batth, T.S.; Olsen, J.V.; et al. Proteome and phosphoproteome changes associated with prognosis in acute myeloid leukemia. Cancers 2020, 12. [CrossRef]

23. Aasebø, E.; Berven, F.S.; Hovland, R.; Døskeland, S.O.; Bruserud, Ø.; Selheim, F.; Hernandez-Valladares, M. The progression of acute myeloid leukemia from first diagnosis to chemoresistant relapse: A comparison of proteomic and phosphoproteomic profiles. Cancers 2020, 12. [CrossRef]

24. Franchin, C.; Cesaro, L.; Salvi, M.; Millioni, R.; Iori, E.; Cifani, P.; James, P.; Arrigoni, G.; Pinna, L. Quantitative analysis of a phosphoproteome readily altered by the protein kinase CK2 inhibitor quinalizarin in HEK-293T cells. Biochim. Biophys. Acta 2015, 1854, 609-623. [CrossRef]

25. Rusin, S.F.; Adamo, M.E.; Kettenbach, A.N. Identification of candidate casein kinase 2 substrates in mitosis by quantitative phosphoproteomics. Front. Cell Dev. Biol. 2017, 5, 97. [CrossRef]

26. Perera, Y.; Ramos, Y.; Padrón, G.; Caballero, E.; Guirola, O.; Caligiuri, L.G.; Lorenzo, N.; Gottardo, F.; Farina, H.G.; Filhol, O.; et al. CIGB-300 anticancer peptide regulates the protein kinase CK2-dependent phosphoproteome. Mol. Cell Biochem. 2020, 470, 63-75. [CrossRef] [PubMed]

27. Franchin, C.; Borgo, C.; Cesaro, L.; Zaramella, S.; Vilardell, J.; Salvi, M.; Arrigoni, G.; Pinna, L.A. Re-evaluation of protein kinase CK2 pleiotropy: New insights provided by a phosphoproteomics analysis of CK2 knockout cells. Cell. Mol. Life Sci. CMLS 2018, 75, 2011-2026. [CrossRef] 
28. Wiśniewski, J.R.; Mann, M. Consecutive proteolytic digestion in an enzyme reactor increases depth of proteomic and phosphoproteomic analysis. Anal. Chem. 2012, 84, 2631-2637. [CrossRef] [PubMed]

29. Wiśniewski, J.R.; Nagaraj, N.; Zougman, A.; Gnad, F.; Mann, M. Brain phosphoproteome obtained by a FASP-based method reveals plasma membrane protein topology. J. Proteom. Res. 2010, 9, 3280-3289. [CrossRef]

30. Rappsilber, J.; Ishihama, Y.; Mann, M. Stop and go extraction tips for matrix-assisted laser desorption/ionization, nanoelectrospray, and LC/MS sample pretreatment in proteomics. Anal. Chem. 2003, 75, 663-670. [CrossRef]

31. Cox, J.; Hein, M.Y.; Luber, C.A.; Paron, I.; Nagaraj, N.; Mann, M. Accurate proteome-wide label-free quantification by delayed normalization and maximal peptide ratio extraction, termed MaxLFQ. Mol. Cell. Proteom. MCP 2014, 13, 2513-2526. [CrossRef] [PubMed]

32. Tyanova, S.; Temu, T.; Sinitcyn, P.; Carlson, A.; Hein, M.Y.; Geiger, T.; Mann, M.; Cox, J. The Perseus computational platform for comprehensive analysis of (prote)omics data. Nat. Methods 2016, 13, 731-740. [CrossRef] [PubMed]

33. Ashburner, M.; Ball, C.A.; Blake, J.A.; Botstein, D.; Butler, H.; Cherry, J.M.; Davis, A.P.; Dolinski, K.; Dwight, S.S.; Eppig, J.T.; et al. Gene ontology: Tool for the unification of biology. The gene ontology consortium. Nat. Genet. 2000, 25, 25-29. [CrossRef] [PubMed]

34. Gene Ontology Consortium. The gene ontology resource: 20 years and still GOing strong. Nucleic Acids Res. 2019, 47, D330-D338. [CrossRef]

35. Huang, D.W.; Sherman, B.T.; Lempicki, R.A. Systematic and integrative analysis of large gene lists using DAVID bioinformatics resources. Nat. Protoc. 2009, 4, 44-57. [CrossRef]

36. Huang, D.W.; Sherman, B.T.; Lempicki, R.A. Bioinformatics enrichment tools: Paths toward the comprehensive functional analysis of large gene lists. Nucleic Acids Res. 2009, 37, 1-13. [CrossRef]

37. Supek, F.; Bošnjak, M.; Škunca, N.; Šmuc, T. REVIGO summarizes and visualizes long lists of gene ontology terms. PLoS ONE 2011, 6, e21800. [CrossRef]

38. Crooks, G.E.; Hon, G.; Chandonia, J.M.; Brenner, S.E. WebLogo: A sequence logo generator. Genome Res. 2004, 14, 1188-1190. [CrossRef]

39. Huang, H.; Arighi, C.N.; Ross, K.E.; Ren, J.; Li, G.; Chen, S.C.; Wang, Q.; Cowart, J.; Vijay-Shanker, K.; Wu, C.H. iPTMnet: An integrated resource for protein post-translational modification network discovery. Nucleic Acids Res. 2018, 46, D542-D550. [CrossRef]

40. Hornbeck, P.V.; Zhang, B.; Murray, B.; Kornhauser, J.M.; Latham, V.; Skrzypek, E. PhosphoSitePlus, 2014: Mutations, PTMs and recalibrations. Nucleic Acids Res. 2015, 43, D512-D520. [CrossRef]

41. Dinkel, H.; Chica, C.; Via, A.; Gould, C.M.; Jensen, L.J.; Gibson, T.J.; Diella, F. Phospho.ELM: A database of phosphorylation sites-Update 2011. Nucleic Acids Res. 2011, 39, D261-D267. [CrossRef]

42. Lachmann, A.; Ma'ayan, A. KEA: Kinase enrichment analysis. Bioinformatics 2009, 25, 684-686. [CrossRef]

43. Zhou, Y.; Zhou, B.; Pache, L.; Chang, M.; Khodabakhshi, A.H.; Tanaseichuk, O.; Benner, C.; Chanda, S.K. Metascape provides a biologist-oriented resource for the analysis of systems-level datasets. Nat. Commun. 2019, 10, 1523. [CrossRef] [PubMed]

44. Bader, G.D.; Hogue, C.W. An automated method for finding molecular complexes in large protein interaction networks. BMC Bioinform. 2003, 4, 2. [CrossRef]

45. Linding, R.; Jensen, L.J.; Pasculescu, A.; Olhovsky, M.; Colwill, K.; Bork, P.; Yaffe, M.B.; Pawson, T. NetworKIN: A resource for exploring cellular phosphorylation networks. Nucleic Acids Res. 2008, 36, D695-D699. [CrossRef]

46. Bian, Y.; Ye, M.; Wang, C.; Cheng, K.; Song, C.; Dong, M.; Pan, Y.; Qin, H.; Zou, H. Global screening of CK2 kinase substrates by an integrated phosphoproteomics workflow. Sci. Rep. 2013, 3, 3460. [CrossRef] [PubMed]

47. Szklarczyk, D.; Gable, A.L.; Lyon, D.; Junge, A.; Wyder, S.; Huerta-Cepas, J.; Simonovic, M.; Doncheva, N.T.; Morris, J.H.; Bork, P.; et al. STRING v11: Protein-protein association networks with increased coverage, supporting functional discovery in genome-wide experimental datasets. Nucleic Acids Res. 2019, 47, D607-D613. [CrossRef]

48. Shannon, P.; Markiel, A.; Ozier, O.; Baliga, N.S.; Wang, J.T.; Ramage, D.; Amin, N.; Schwikowski, B.; Ideker, T. Cytoscape: A software environment for integrated models of biomolecular interaction networks. Genome Res. 2003, 13, 2498-2504. [CrossRef]

49. Pierre, F.; Chua, P.C.; O’Brien, S.E.; Siddiqui-Jain, A.; Bourbon, P.; Haddach, M.; Michaux, J.; Nagasawa, J.; Schwaebe, M.K.; Stefan, E.; et al. Pre-clinical characterization of CX-4945, a potent and selective small molecule inhibitor of CK2 for the treatment of cancer. Mol. Cell. Biochem. 2011, 356, 37-43. [CrossRef]

50. Hanson, C.A.; Alkan, S. Acute leukemias and myelodysplastic syndromes. In Clinical Laboratory Medicine, 2nd ed.; McClatchey, K.D., Ed.; Lippincott Williams \& Wilkins: Philadelphia, PA, USA, 2002; p. 909.

51. Tubi, L.Q.; Gurrieri, C.; Brancalion, A.; Bonaldi, L.; Bertorelle, R.; Manni, S.; Pavan, L.; Lessi, F.; Zambello, R.; Trentin, L.; et al. Inhibition of protein kinase CK2 with the clinical-grade small ATP-competitive compound CX-4945 or by RNA interference unveils its role in acute myeloid leukemia cell survival, p53-dependent apoptosis and daunorubicin-induced cytotoxicity. $J$. Hematol. Oncol. 2013, 6, 78. [CrossRef] [PubMed]

52. Rabalski, A.J.; Gyenis, L.; Litchfield, D.W. Molecular pathways: Emergence of protein kinase CK2 (CSNK2) as a potential target to inhibit survival and DNA damage response and repair pathways in cancer cells. Clin. Cancer Res. Off. J. Am. Assoc. Cancer Res. 2016, 22, 2840-2847. [CrossRef]

53. Bensimon, A.; Schmidt, A.; Ziv, Y.; Elkon, R.; Wang, S.Y.; Chen, D.J.; Aebersold, R.; Shiloh, Y. ATM-dependent and -independent dynamics of the nuclear phosphoproteome after DNA damage. Sci. Signal. 2010, 3, rs3. [CrossRef]

54. Bennetzen, M.V.; Larsen, D.H.; Bunkenborg, J.; Bartek, J.; Lukas, J.; Andersen, J.S. Site-specific phosphorylation dynamics of the nuclear proteome during the DNA damage response. Mol. Cell. Proteom. MCP 2010, 9, 1314-1323. [CrossRef] 
55. Siddiqui-Jain, A.; Bliesath, J.; Macalino, D.; Omori, M.; Huser, N.; Streiner, N.; Ho, C.B.; Anderes, K.; Proffitt, C.; O’Brien, S.E.; et al. CK2 inhibitor CX-4945 suppresses DNA repair response triggered by DNA-targeted anticancer drugs and augments efficacy: Mechanistic rationale for drug combination therapy. Mol. Cancer 2012, 11, 994-1005. [CrossRef] [PubMed]

56. Perera, Y.; Toro, N.D.; Gorovaya, L.; Fernandez, D.E.C.J.; Farina, H.G.; Perea, S.E. Synergistic interactions of the anti-casein kinase 2 CIGB-300 peptide and chemotherapeutic agents in lung and cervical preclinical cancer models. Mol. Clin. Oncol. 2014, 2, 935-944. [CrossRef] [PubMed]

57. Keating, J.A.; Striker, R. Phosphorylation events during viral infections provide potential therapeutic targets. Rev. Med. Virol. 2012, 22, 166-181. [CrossRef]

58. Songyang, Z.; Lu, K.P.; Kwon, Y.T.; Tsai, L.H.; Filhol, O.; Cochet, C.; Brickey, D.A.; Soderling, T.R.; Bartleson, C.; Graves, D.J.; et al A structural basis for substrate specificities of protein Ser/Thr kinases: Primary sequence preference of casein kinases I and II, NIMA, phosphorylase kinase, calmodulin-dependent kinase II, CDK5, and Erk1. Mol. Cell. Biol. 1996, 16, 6486-6493. [CrossRef]

59. Ballif, B.A.; Villén, J.; Beausoleil, S.A.; Schwartz, D.; Gygi, S.P. Phosphoproteomic analysis of the developing mouse brain. Mol. Cell. Proteom. MCP 2004, 3, 1093-1101. [CrossRef] [PubMed]

60. Marin, O.; Meggio, F.; Draetta, G.; Pinna, L.A. The consensus sequences for cdc2 kinase and for casein kinase-2 are mutually incompatible. A study with peptides derived from the beta-subunit of casein kinase-2. FEBS Lett. 1992, 301, 111-114. [CrossRef]

61. Guo, X.; Williams, J.G.; Schug, T.T.; Li, X. DYRK1A and DYRK3 promote cell survival through phosphorylation and activation of SIRT1. J. Biol. Chem. 2010, 285, 13223-13232. [CrossRef]

62. Alvarez, M.; Altafaj, X.; Aranda, S.; De la Luna, S. DYRK1A autophosphorylation on serine residue 520 modulates its kinase activity via 14-3-3 binding. Mol. Biol. Cell 2007, 18, 1167-1178. [CrossRef] [PubMed]

63. De Graaf, K.; Hekerman, P.; Spelten, O.; Herrmann, A.; Packman, L.C.; Büssow, K.; Müller-Newen, G.; Becker, W. Characterization of cyclin L2, a novel cyclin with an arginine/serine-rich domain: Phosphorylation by DYRK1A and colocalization with splicing factors. J. Biol. Chem. 2004, 279, 4612-4624. [CrossRef] [PubMed]

64. Plotnikov, A.; Chuderland, D.; Karamansha, Y.; Livnah, O.; Seger, R. Nuclear ERK translocation is mediated by protein kinase CK2 and accelerated by autophosphorylation. Cell. Physiol. Biochem. Int. J. Exp. Cell. Physiol. Biochem. Pharmacol. 2019, 53, 366-387. [CrossRef]

65. Yamane, K.; Kinsella, T.J. Casein kinase 2 regulates both apoptosis and the cell cycle following DNA damage induced by 6-thioguanine. Clin. Cancer Res. Off. J. Am. Assoc. Cancer Res. 2005, 11, 2355-2363. [CrossRef]

66. Di Maira, G.; Salvi, M.; Arrigoni, G.; Marin, O.; Sarno, S.; Brustolon, F.; Pinna, L.A.; Ruzzene, M. Protein kinase CK2 phosphorylates and upregulates Akt/PKB. Cell Death Differ. 2005, 12, 668-677. [CrossRef] [PubMed]

67. Silva, A.; Yunes, J.A.; Cardoso, B.A.; Martins, L.R.; Jotta, P.Y.; Abecasis, M.; Nowill, A.E.; Leslie, N.R.; Cardoso, A.A.; Barata, J.T. PTEN posttranslational inactivation and hyperactivation of the PI3K/Akt pathway sustain primary T cell leukemia viability. J. Clin. Investig. 2008, 118, 3762-3774. [CrossRef] [PubMed]

68. Tubi, L.Q.; Nunes, S.C.; Brancalion, A.; Breatta, E.D.; Manni, S.; Mandato, E.; Zaffino, F.; Macaccaro, P.; Carrino, M.; Gianesin, K.; et al. Protein kinase CK2 regulates AKT, NF- $\mathrm{KB}$ and STAT3 activation, stem cell viability and proliferation in acute myeloid leukemia. Leukemia 2017, 31, 292-300. [CrossRef] [PubMed]

69. Buontempo, F.; Orsini, E.; Martins, L.R.; Antunes, I.; Lonetti, A.; Chiarini, F.; Tabellini, G.; Evangelisti, C.; Evangelisti, C.; Melchionda, F.; et al. Cytotoxic activity of the casein kinase 2 inhibitor CX-4945 against T-cell acute lymphoblastic leukemia: Targeting the unfolded protein response signaling. Leukemia 2014, 28, 543-553. [CrossRef]

70. Buontempo, F.; Orsini, E.; Lonetti, A.; Cappellini, A.; Chiarini, F.; Evangelisti, C.; Evangelisti, C.; Melchionda, F.; Pession, A.; Bertaina, A.; et al. Synergistic cytotoxic effects of bortezomib and CK2 inhibitor CX-4945 in acute lymphoblastic leukemia: Turning off the prosurvival ER chaperone BIP/Grp78 and turning on the pro-apoptotic NF-кB. Oncotarget 2016, 7, 1323-1340. [CrossRef]

71. Machyna, M.; Kehr, S.; Straube, K.; Kappei, D.; Buchholz, F.; Butter, F.; Ule, J.; Hertel, J.; Stadler, P.F.; Neugebauer, K.M. The coilin interactome identifies hundreds of small noncoding RNAs that traffic through Cajal bodies. Mol. Cell 2014, 56, 389-399. [CrossRef]

72. Kofuji, S.; Hirayama, A.; Eberhardt, A.O.; Kawaguchi, R.; Sugiura, Y.; Sampetrean, O.; Ikeda, Y.; Warren, M.; Sakamoto, N.; Kitahara, S.; et al. IMP dehydrogenase-2 drives aberrant nucleolar activity and promotes tumorigenesis in glioblastoma. Nat. Cell Biol. 2019, 21, 1003-1014. [CrossRef] [PubMed]

73. Duan, S.; Huang, W.; Liu, X.; Liu, X.; Chen, N.; Xu, Q.; Hu, Y.; Song, W.; Zhou, J. IMPDH2 promotes colorectal cancer progression through activation of the PI3K/AKT/mTOR and PI3K/AKT/FOXO1 signaling pathways. J. Exp. Clin. Cancer Res. 2018, 37, 304. [CrossRef] [PubMed]

74. Mosimann, C.; Hausmann, G.; Basler, K. Parafibromin/hyrax activates Wnt/Wg target gene transcription by direct association with beta-catenin/armadillo. Cell 2006, 125, 327-341. [CrossRef]

75. Seldin, D.C.; Landesman-Bollag, E.; Farago, M.; Currier, N.; Lou, D.; Dominguez, I. CK2 as a positive regulator of Wnt signalling and tumourigenesis. Mol. Cell Biochem. 2005, 274, 63-67. [CrossRef]

76. Jin, C.; Song, P.; Pang, J. The CK2 inhibitor CX4945 reverses cisplatin resistance in the A549/DDP human lung adenocarcinoma cell line. Oncol. Lett. 2019, 18, 3845-3856. [CrossRef]

77. Palvimo, J.; Linnala-Kankkunen, A. Identification of sites on chromosomal protein HMG-I phosphorylated by casein kinase II. FEBS Lett. 1989, 257, 101-104. [CrossRef]

78. Louie, D.F.; Gloor, K.K.; Galasinski, S.C.; Resing, K.A.; Ahn, N.G. Phosphorylation and subcellular redistribution of high mobility group proteins 14 and 17, analyzed by mass spectrometry. Protein Sci. A Publ. Protein Soc. 2000, 9, 170-179. [CrossRef] 
79. Jiang, X.G.; Wang, Y. Phosphorylation of human high mobility group N1 protein by protein kinase CK2. Biochem. Biophys. Res. Commun. 2006, 345, 1497-1503. [CrossRef]

80. Reeves, R. Nuclear functions of the HMG proteins. Biochim. Biophys. Acta 2010, 1799, 3-14. [CrossRef]

81. Yang, D.; Han, Z.; Alam, M.M.; Oppenheim, J.J. High-mobility group nucleosome binding domain 1 (HMGN1) functions as a Th1-polarizing alarmin. Semin. Immunol. 2018, 38, 49-53. [CrossRef]

82. Yoh, S.M.; Cho, H.; Pickle, L.; Evans, R.M.; Jones, K.A. The Spt6 SH2 domain binds Ser2-P RNAPII to direct Iws1-dependent mRNA splicing and export. Genes Dev. 2007, 21, 160-174. [CrossRef] [PubMed]

83. Yoh, S.M.; Lucas, J.S.; Jones, K.A. The Iws1:Spt6:CTD complex controls cotranscriptional mRNA biosynthesis and HYPB/Setd2mediated histone H3K36 methylation. Genes Dev. 2008, 22, 3422-3434. [CrossRef]

84. Mayrand, S.H.; Dwen, P.; Pederson, T. Serine/threonine phosphorylation regulates binding of C hnRNP proteins to pre-mRNA. Proc. Natl. Acad. Sci. USA 1993, 90, 7764-7768. [CrossRef]

85. Stone, J.R.; Maki, J.L.; Collins, T. Basal and hydrogen peroxide stimulated sites of phosphorylation in heterogeneous nuclear ribonucleoprotein C1/C2. Biochemistry 2003, 42, 1301-1308. [CrossRef]

86. Borgo, C.; Franchin, C.; Salizzato, V.; Cesaro, L.; Arrigoni, G.; Matricardi, L.; Pinna, L.A.; Donella-Deana, A. Protein kinase CK2 potentiates translation efficiency by phosphorylating eIF3j at Ser127. Biochim. Biophys. Acta 2015, 1853, 1693-1701. [CrossRef] [PubMed]

87. Llorens, F.; Duarri, A.; Sarró, E.; Roher, N.; Plana, M.; Itarte, E. The N-terminal domain of the human eIF2beta subunit and the CK2 phosphorylation sites are required for its function. Biochem. J. 2006, 394, 227-236. [CrossRef]

88. Rossi, R.; Villa, A.; Negri, C.; Scovassi, I.; Ciarrocchi, G.; Biamonti, G.; Montecucco, A. The replication factory targeting sequence/PCNA-binding site is required in $\mathrm{G}(1)$ to control the phosphorylation status of DNA ligase I. EMBO J. 1999, 18, 5745-5754. [CrossRef] [PubMed]

89. Shah, P.; Zhao, B.; Qiang, L.; He, Y.Y. Phosphorylation of xeroderma pigmentosum group C regulates ultraviolet-induced DNA damage repair. Nucleic Acids Res. 2018, 46, 5050-5060. [CrossRef]

90. Lees-Miller, S.P.; Anderson, C.W. Two human 90-kDa heat shock proteins are phosphorylated in vivo at conserved serines that are phosphorylated in vitro by casein kinase II. J. Biol. Chem. 1989, 264, 2431-2437. [CrossRef]

91. Bagatell, R.; Whitesell, L. Altered Hsp90 function in cancer: A unique therapeutic opportunity. Mol. Cancer 2004, 3, 1021-1030.

92. Manni, S.; Brancalion, A.; Tubi, L.Q.; Colpo, A.; Pavan, L.; Cabrelle, A.; Ave, E.; Zaffino, F.; Di Maira, G.; Ruzzene, M.; et al. Protein kinase CK2 protects multiple myeloma cells from ER stress-induced apoptosis and from the cytotoxic effect of HSP90 inhibition through regulation of the unfolded protein response. Clin. Cancer Res. Off. J. Am. Assoc. Cancer Res. 2012, 18, 1888-1900. [CrossRef] [PubMed] 